\title{
Evidence-Based Guidelines for the Treatment of Helicobacter pylori Infection in Korea 2020
}

\author{
Hye-Kyung Jung ${ }^{1}$, Seung Joo Kang ${ }^{2}$, Yong Chan Lee ${ }^{3}$, Hyo-Joon Yang ${ }^{4}$, Seon-Young Park ${ }^{5}$, Cheol Min Shin 6 , \\ Sung Eun Kim${ }^{7}$, Hyun Chul Lim ${ }^{8}$, Jie-Hyun Kim${ }^{9}$, Su Youn Nam ${ }^{10}$, Woon Geon Shin ${ }^{11}$, Jae Myung Park ${ }^{12}$, II Ju \\ $\mathrm{Choi}^{13}$, Jae Gyu Kim ${ }^{14}$, and Miyoung Choi ${ }^{15}$, Korean College of Helicobacter and Upper Gastrointestinal Research \\ ${ }^{1}$ Department of Internal Medicine, Ewha Womans University School of Medicine, ${ }^{2}$ Department of Internal Medicine, Seoul National \\ University Hospital Gangnam Center, ${ }^{3}$ Department of Internal Medicine, Yonsei University College of Medicine, ${ }^{4}$ Division of \\ Gastroenterology, Department of Internal Medicine and Gastrointestinal Cancer Center, Kangbuk Samsung Hospital, Sungkyunkwan \\ University School of Medicine, Seoul, ${ }^{5}$ Department of Internal Medicine, Chonnam National University Medical School, Gwangju, \\ ${ }^{6}$ Department of Internal Medicine, Seoul National University Bundang Hospital, Seongnam, ${ }^{7}$ Department of Internal Medicine, Kosin \\ University College of Medicine, Busan, ${ }^{8}$ Department of Internal Medicine, Yongin Severance Hospital, Yonsei University College of \\ Medicine, Yongin, ${ }^{9}$ Department of Internal Medicine and Institute of Gastroenterology, Yonsei University College of Medicine, Seoul, \\ ${ }^{10}$ Center for Gastric Cancer, Kyungpook National University Hospital Chilgok Hospital, School of Medicine, Kyungpook National \\ University, Daegu, ${ }^{11}$ Department of Internal Medicine, Hallym University College of Medicine, ${ }^{12}$ Division of Gastroenterology and \\ Hepatology, Department of Internal Medicine, Seoul St. Mary's Hospital, College of Medicine, The Catholic University of Korea, Seoul, \\ ${ }^{13}$ Center for Gastric Cancer, National Cancer Center, Goyang, ${ }^{14}$ Department of Internal Medicine, Chung-Ang University College of \\ Medicine, and ${ }^{15}$ Division of Healthcare Technology Assessment Research, National Evidence-based Healthcare Collaborating Agency, \\ Seoul, Korea
}

\author{
Article Info \\ Received September 7, 2020 \\ Revised October 14, 2020 \\ Accepted October 20, 2020 \\ Published online January 22, 2021

\section{Corresponding Author} \\ Yong Chan Lee \\ ORCID https://orcid.org/0000-0001-8800-6906 \\ E-mail leeyc@yuhs.ac
}

Hye-Kyung Jung and Seung Joo Kang contributed equally to this work as first authors.
Helicobacter pylori infection is one of the most common infectious diseases worldwide. Although the prevalence of $H$. pylori is gradually decreasing, approximately half of the world's population still becomes infected with this disease. $H$. pylori is responsible for substantial gastrointestinal morbidity worldwide, with a high disease burden. It is the most common cause of gastric and duodenal ulcers and gastric cancer. Since the revision of the $H$. pylori clinical practice guidelines in 2013 in Korea, the eradication rate of $H$. pylori has gradually decreased with the use of a clarithromycin-based triple therapy for 7 days. According to a nationwide randomized controlled study conducted by the Korean College of Helicobacter and Upper Gastrointestinal Research released in 2018 , the intention-to-treat eradication rate was only $63.9 \%$, which was mostly due to increased antimicrobial resistance, especially from clarithromycin. The clinical practice guidelines for the treatment of $\mathrm{H}$. pylori were updated according to evidence-based medicine from a meta-analysis conducted on a target group receiving the latest level of eradication therapy. The draft recommendations developed based on the meta-analysis were finalized after an expert consensus on three recommendations regarding the indication for treatment and eight recommendations for the treatment itself. These guidelines were designed to provide clinical evidence for the treatment (including primary care treatment) of $H$. pylori infection to patients, nurses, medical school students, policymakers, and clinicians. These may differ from current medical insurance standards and will be revised if more evidence emerges in the future. (Gut Liver 2021;15:168-195)

Key Words: Helicobacter pylori; Guidelines; Treatment; Meta-analysis; Microbial sensitivity tests

\section{INTRODUCTION}

\section{Background}

Helicobacter pylori infection is the most common cause of infectious disease in the world. Its prevalence varies worldwide, e.g., $11 \%$ in Northern Europe, $23.1 \%$ in Canada, and $30.0 \%$ in the United States, but compared to $72 \%$ to $80 \%$ in South America and 91\% in Nigeria. ${ }^{1}$ The preva-

\section{Copyright $\odot$ Gut and Liver.} (C) (i) 1 This is an Open Access article distributed under the terms of the Creative Commons Attribution Non-Commercial License (http://creativecommons.org/licenses/by-nc/4.0)
which permits unrestricted non-commercial use, distribution, and reproduction in any medium, provided the original work is properly cited. 
lence is $50 \%$ higher in Korea. ${ }^{2} \mathrm{H}$. pylori causes progressive injury to the gastric mucosa and play an important role in gastrointestinal diseases such as asymptomatic chronic gastritis, peptic ulcer disease, atrophic gastritis, intestinal metaplasia (IM), gastric mucosa-associated lymphoid tissue lymphoma and gastric adenocarcinoma. ${ }^{3,4}$

Many epidemiologic studies have shown the relationship between $H$. pylori and gastric cancer. The Asia-Pacific region (China, Japan, and Korea) which has a high risk of gastric cancer shows a high prevalence of $H$. pylori infection. In 2017, the standardized incidence of gastric cancer in Korea was 32.0 per 100,000 person, which was a leading cause of cancer second to thyroid cancer. ${ }^{4,5}$ Considering the high prevalence and high fatality in advanced cases of gastric cancer, finding effective measures for primary or secondary prevention of gastric cancer is a public health priority. In 2013, the Japanese health insurance has begun covering eradication therapy for $H$. pylori-positive gastritis, even though there is no concrete evidence on the eradication therapy for $H$. pylori gastritis. ${ }^{6,7}$ However, it is not clear whether there is a definite benefit compared to the harms due to their high cost and potential increase in antibiotic resistance with mass eradication therapy to $H$. pylori infection. In 2013, clinical practice guidelines for diagnosis and treatment of $H$. pylori infection were developed to address domestic situations with an adaptation process. ${ }^{8}$

The present revision of previous guidelines intended to generate evidence by conducting a systematic review of the additive indication such as eradication therapy of $H$. pylori in patients with unexplained iron deficiency anemia (IDA), post-endoscopic resection (ER) of gastric adenoma and atrophy gastritis and/or IM.

For effective eradication, multi-antibiotics regimens with anti-secretory agents are used. Unsuccessful eradication is associated with high bacterial load, high gastric acidity, the virulence of Helicobacter strains and poor compliance. However, growing antibiotics resistance, particularly clarithromycin resistance seems to be the major cause of decreasing eradication rate. ${ }^{9}$

In the last 20 years, a widespread use of antibiotics, such as clarithromycin for respiratory symptoms and levofloxacin for urinary infection, has increased the primary $H$. pylori resistance in many countries. ${ }^{10}$ Systematic review revealed that the overall $H$. pylori antibiotic resistance rates were $17.2 \%$ (95\% confidence interval [CI], 16.5\% to $17.9 \%$ ) for clarithromycin, $26.7 \%$ (95\% CI, $25.2 \%$ to $28.1 \%$ ) for metronidazole, and $11.2 \%$ (95\% CI, $9.6 \%$ to $12.7 \%$ ) for amoxicillin. ${ }^{10}$ Based on these changes, European guidelines recommended to extend the standard triple therapy to 14 days where clarithromycin resistance was $>15 \%-20 \% .{ }^{11}$ In Korea, the clarithromycin resistance rates rose from $9 \%$ in
1995 and $13.8 \%$ in 2003 to $16.7 \%$ in 2005 , and $17.8 \%$ in a nationwide study in 2018, ${ }^{2,12-14}$

With dynamic changes of the epidemiology of $H$. pylori and increasing issue of antibiotics resistance, a new approach is needed for effective management. In these updated guidelines, we aimed to present the appropriate H. pylori treatment for Korea by conducting systematic review and meta-analysis to identify the clinical evidence for alternative treatments to the standard 7-day triple therapy.

\section{METHODS}

\section{Revision process}

1) Guidelines development organization

The Steering Committee which consisted of the President and the executive members of the Korean College of Helicobacter and Upper Gastrointestinal Research established development strategies, appointed working group members, and approved budgets related to the project.

This guideline included multidisciplinary processes by the Korean Society of Clinical Microbiology, the Korean Society of Pathologists, and the Korean Society of Gastroenterology. To establish the methodology for developing guidelines, two methodological experts (Miyoung Choi and Ein Soon Shin) and Professor Soo Young Kim, a member of the Korean Medical Association's Clinical Treatment Guidelines Development Committee, conducted four workshops on the literature search, quality assessment, meta-analysis, and methods of expert consensus.

In the course of developing or approving the guidelines, the members of the working group were asked to confirm that they had no conflict of interest by accepting advice or employment from commercially relevant organizations, commercial ownership interests, research funds, and case fees, or intellectual property rights (e.g., patents, trademarks, licensing or royalties) for drugs related to the development of the guidelines, and whether their families had the same relationship as those described above.

\section{2) Patient's preference and perspective}

A web survey using structured questionnaires was administered to the largest Internet community associated with gastrointestinal diseases was to identify the experiences, expectations and preferences of patients in this guideline. A total of 233 subjects responded, $64.4 \%$ of whom were adult women and $57.5 \%$ of whom were $H$. pylori-positive. Among those who were positive for $H$. $p y$ lori, $86.7 \%$ wanted treatment, the reasons for which were for prevention of stomach cancer (44.6\%), improvement of stomach symptoms (28.8\%), and fear of transmitting infec- 
tion to others (9.9\%). The most worrisome aspect of the $H$. pylori treatment was $80.3 \%$ of the drug's adverse reactions. Based on these points, the topic of adverse effect of eradication therapy and the impact of $H$. pylori eradication on gastric adenoma after ER of neoplastic lesions in the stomach, atrophic gastritis and IM, and the precursor to gastric cancer were added as key questions.

\section{3) Guideline development process}

The scope of clinical practice guidelines was determined by deriving key questions tailored to the PICO (populationintervention-comparison-outcome) format using nominal group techniques in working group. ${ }^{15}$ De novo method was implemented in this revision because the guidelines required the latest evidence as the dynamics of the $H$. pylori infection and related gastrointestinal diseases in Korea are changing rapidly.

\section{(1) Systematic review and meta-analysis}

A systematic review was conducted at each PICO. Dr. Miyoung Choi of the National Evidence-based Healthcare Collaborating Agency and a working group member of each subject selected appropriate search key words and conducted a literature search from July to August 2018 using the Ovid-MEDLINE, EMBASE, Cochrane Library,
KoreaMed and KMBASE databases; the key words were listed in the appendix. The common inclusion criteria for the studies were as follows: (1) adult subjects or patients as the study population, (2) written in English or Korean, (3) systematic reviews and meta-analyses, randomized or non-randomized trials, and observational studies, (4) published between 2008 and 2018, and (5) studies with proper results reported. The common exclusion criteria were as follows: (1) studies on children or teenagers, (2) studies with no proper results reported, (3) duplicated publication, (4) impossible to obtain original text, and (5) expert opinion, case series or report, narrative review, or guidelines. Two independent members reviewed the literatures and selected the final studies according to the inclusion and exclusion criteria. The literature selection process was summarized in the Preferred Reporting Items for Systematic Reviews and Meta-Analysis (PRISMA) plot for each PICO. An example of the process of literature selection for key question 1 is shown in Fig. 1. The quality of finally selected studies was assessed using quality assessment tools according to the study design. Randomized controlled trials (RCTs) were evaluated using the Cochrane Risk of Bias (RoB) tool, ${ }^{16}$ while non-randomized clinical studies were assessed using the Risk of Bias Assessment Tool for Nonrandomized Study (RoBANS). ${ }^{17}$ If the assessments were

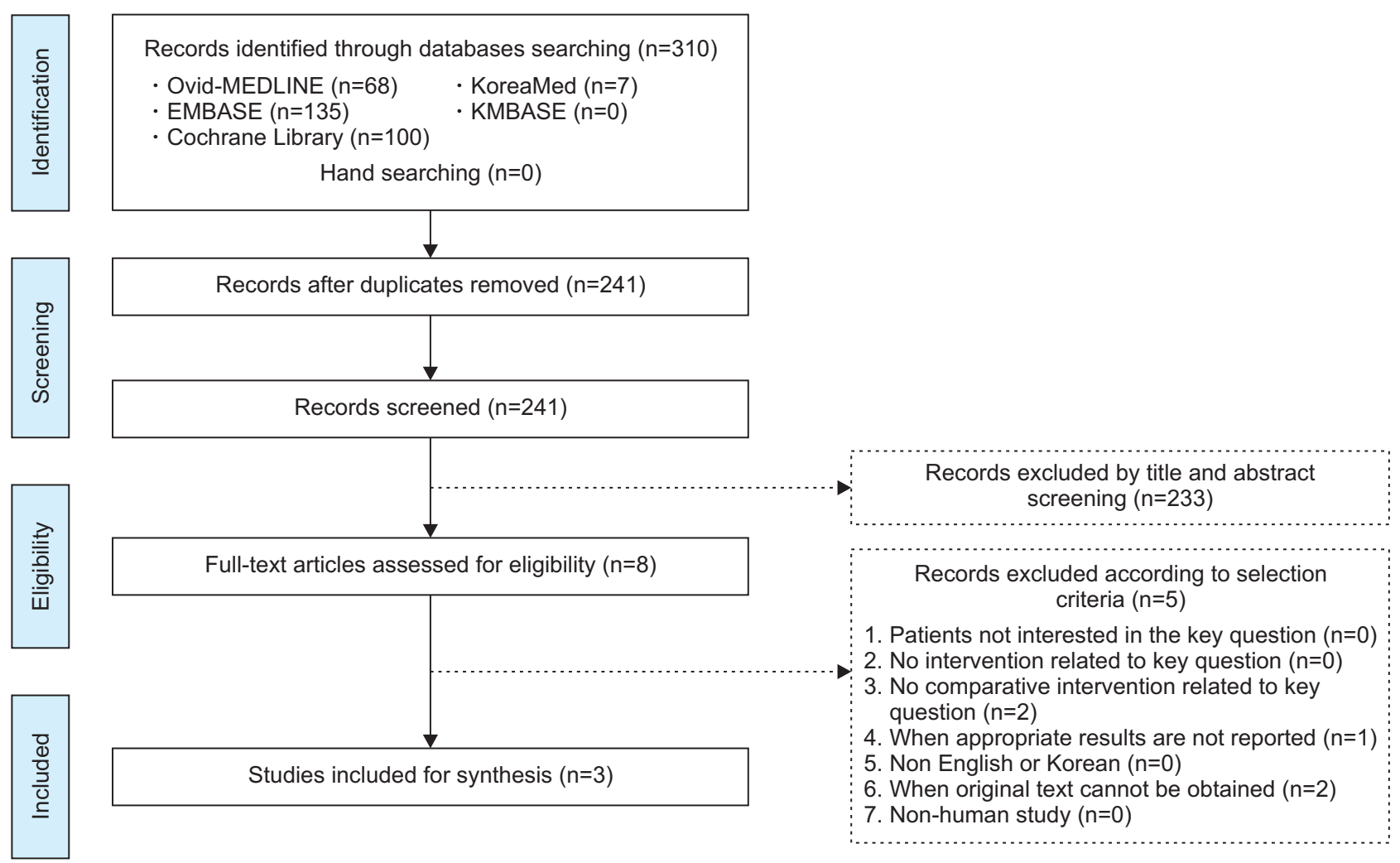

Fig. 1. Preferred Reporting Items for Systematic Reviews and Meta-Analysis (PRISMA) flowchart showing the selection process for key question 1. 
not consistent as the two paired working members, the two members and the chairman coordinated a final evaluation.

\section{(2) Elicitation of recommendations: level of evidence and grade of recommendation}

After systematic literature review, the evidence table was organized and meta-analysis was conducted. Evidence profiles were created based on "Grading of Recommendations, Assessment, Development and Evaluation (GRADE)" (Table 1). ${ }^{18}$ GRADEpro software was used to rank the quality of evidence according to four categories: high, moderate, low, and very low. The quality assessment of the evidence was then used to determine the strength of the supporting evidence that informs a recommendation (Table 2). ${ }^{19}$

A literature search was conducted to utilize resources and economic evaluation. The cost of $H$. pylori eradication, which uses antibiotics and proton pump inhibitors (PPIs) for 7-14 days, was not significantly different between the treatment methods. The tailored therapy based on $H$. pylori susceptibility to antibiotics may be cost-effective in a high clarithromycin-resistant region compared to standard empirical triple therapy. There are reports that tailored treatment is superior in terms of cost-effectiveness if the eradication rate of $H$. pylori is lowered below $75.3 \%$. Therefore, the tailored treatment based on $H$. pylori susceptibility to antibiotics was added to the recommendation. ${ }^{20,21}$

\section{(3) Expert consensus with modified Delphi agreement process}

The aim of expert consensus by modified Delphi methods was to determine the extent to which experts agreed about draft recommendation including evidence. ${ }^{22}$ The first round of Delphi process was conducted with E-mail voting and 44 experts were invited, with 30 participating in the first agreement. The first round was investigated using the 9-Likert scale self-reporting questionnaire asking the extent of agreement, along with evidence data from the Development Committee for each recommendation. In the response scale, one point was "completely disagreeable" and nine points were "very agreeable." Consent was considered when the ratio of points from 7 to 9 (high agreement) was more than two-thirds without complete disagreement. Eight recommendations were agreed upon for a total of 12 recommendations. Indication of $H$. pylori eradication therapy with IDA and atrophy gastritis/IM and eradication regimen of $H$. pylori with standard triple therapy and sequential therapy failed to reach agreement, so the Development Committee revised these four recommendations after the first voting and conducted the second round of voting in a face-to-face agreement (December 14, 2019). A second round of voting was conducted anonymously, and recommendations for atrophy gastritis/IM were rejected by $48 \%$ of 23 respondents, with the remaining recommendations passed and finally 11 recommendations were adopted.

\section{(4) Internal and external review}

In the second round of face-to-face voting for the expert consensus process, various drafts were adopted after the anonymous vote. After the process of expert agreement and external review, the draft was revised with their opinions.

Table 1. Level of Evidence and Strength of Recommendation

Explanation

\begin{tabular}{|c|c|}
\hline \multicolumn{2}{|l|}{ Class } \\
\hline High & At least one RCT or SR/meta-analysis with no concern of study quality \\
\hline Moderate & $\begin{array}{l}\text { At least one RCT or SR/meta-analysis with minor concern of study quality or } \\
\text { at least one cohort/case-control/diagnostic test design study with no concern of study quality }\end{array}$ \\
\hline Low & $\begin{array}{l}\text { At least one cohort/case-control/diagnostic test study with minor concern of study quality or } \\
\text { at least one single arm before-after study, cross-sectional study with no concern of study quality }\end{array}$ \\
\hline Very low & $\begin{array}{l}\text { At least one cohort/case-control/diagnostic test design study with serious concern of study quality or } \\
\text { at least one single arm before-after study, cross-sectional study with minor/severe concern of study quality }\end{array}$ \\
\hline \multicolumn{2}{|l|}{ Grade classification } \\
\hline Strong for & $\begin{array}{l}\text { The benefit of intervention is greater than harm with high or moderate level of evidence, which can be strongly recom- } \\
\text { mended in most clinical practice. }\end{array}$ \\
\hline Weak for & $\begin{array}{l}\text { The benefit and harm of intervention may vary depending on the clinical situation or patient/social value. It is recom- } \\
\text { mended conditionally according to the clinical situation. }\end{array}$ \\
\hline Against & $\begin{array}{l}\text { The benefit and harm of intervention may vary depending on the clinical situation or patient/social value. Intervention } \\
\text { may not be recommended in clinical practice. }\end{array}$ \\
\hline No recommendation & $\begin{array}{l}\text { It is not possible to determine the recommendation direction owing to a lack of evidence or discrepancy of result. Thus } \\
\text { further evidence is needed. }\end{array}$ \\
\hline
\end{tabular}

RCT, randomized controlled trial; SR, systematic review. 
(5) Dissemination of the guidelines and update information

This guideline was provided on the Korean College of Helicobacter and Upper Gastrointestinal Research (http:// www.hpylori.or.kr) and the Korean Association of Internal Medicine (http://www.kaim.or.kr) websites. In addition, this guideline will be published in Korean and English as a paper and will be spread throughout the academic symposium.

\section{CLINICAL PRACTICE GUIDELINE}

\section{Newly added indication for $H$. pylori eradication}

1) Iron deficiency anemia

Can H. pylori eradication increase the hemoglobin in patients with idiopathic IDA?

Statement 1. H. pylori eradication can be helpful to improve the anemia in subset of adults with unexplained IDA.

Grade of recommendation: weak

Level of evidence: very low
Experts' opinions: completely agree (28.0\%), mostly agree $(48.0 \%)$, partially agree $(10.0 \%)$, mostly disagree $(10.0 \%)$, completely disagree $(5.0 \%)$, not sure $(0 \%)$

Anemia is a major health problem and mostly caused by iron deficiency. ${ }^{23,24}$ The estimated prevalence of anemia is $24.8 \%$ (95\% CI, $22.9 \%$ to $26.7 \%$ ), affecting 1.62 billion people (95\% CI, 1.50 to 1.74 billion) globally, ${ }^{23}$ and concentrated in preschool children and women. H. pylori infection causes diverse gastrointestinal diseases, including chronic gastritis, peptic ulcer disease and cancer. Furthermore, $H$. pylori chronic gastritis can induce decreasing gastric acid secretion and gastric ascorbic acid, which are essential for the absorption of dietary iron. ${ }^{25,26}$

H. pylori has been associated with IDA. A recent metaanalysis revealed a significantly higher likelihood of IDA in subjects with $H$. pylori infection (pooled odds ratio [OR], $1.72 ; 95 \% \mathrm{CI}, 1.23$ to 2.42$){ }^{27}$ However, this association was strong in children, but subgroup analysis of adult population revealed weaker association with significant heterogeneity (pooled OR, 1.70; 95\% CI, 1.01 to 2.85 ). ${ }^{23}$

The role of $H$. pylori infection in IDA was shown in

Table 2. Recommendations for the Treatment of Helicobacter pylori

\begin{tabular}{|c|c|c|c|}
\hline Category & Statements & $\begin{array}{l}\text { Level of } \\
\text { evidences }\end{array}$ & $\begin{array}{l}\text { Strength of } \\
\text { recommendation }\end{array}$ \\
\hline \multirow[t]{3}{*}{ Indications } & $\begin{array}{l}\text { 1. H. pylori eradication can be helpful to improve the anemia in subset of adults with } \\
\text { unexplained iron deficiency anemia. }\end{array}$ & Very low & Weak \\
\hline & $\begin{array}{l}\text { 2. H. pylori eradication can be recommended after endoscopic resection for } \mathrm{H} \text {. pylori- } \\
\text { positive gastric adenoma to prevent metachronous recurrence. }\end{array}$ & Low & Weak \\
\hline & $\begin{array}{l}\text { 3. H. pylori eradication can be recommended for long-term improvement of dyspeptic } \\
\text { symptoms in patients with functional dyspepsia. }\end{array}$ & High & Weak \\
\hline \multirow[t]{5}{*}{ First-line therapy } & $\begin{array}{l}\text { 4. Standard triple therapy (standard dose PPI, amoxicillin } 1 \mathrm{~g} \text {, and clarithromycin } 500 \mathrm{mg} \\
\text { twice daily) for } 14 \text { days is recommended for first-line regimen. }\end{array}$ & Moderate & Strong \\
\hline & $\begin{array}{l}\text { 5. Sequential therapy (standard dose PPI, amoxicillin } 1 \mathrm{~g} \text { twice daily for } 5 \text { days followed } \\
\text { by standard dose PPI, clarithromycin } 500 \mathrm{mg} \text {, and metronidazole } 500 \mathrm{mg} \text { twice daily } \\
\text { for } 5 \text { days) can be one of first-line therapies for } H \text {. pylori eradication. }\end{array}$ & High & Strong \\
\hline & $\begin{array}{l}\text { 6. Concomitant therapy (standard dose PPI, clarithromycin } 500 \mathrm{mg} \text {, amoxicillin } 1 \mathrm{~g} \text {, and } \\
\text { metronidazole } 500 \mathrm{mg} \text { twice daily for } 10 \text { days) is recommended as a first-line treat- } \\
\text { ment. }\end{array}$ & High & Strong \\
\hline & $\begin{array}{l}\text { 7. Clarithromycin resistance test by PCR or sequencing is recommended when a 7-day } \\
\text { standard triple therapy is considered as a first-line treatment. }\end{array}$ & Low & Strong \\
\hline & $\begin{array}{l}\text { 8. Eradication rates of bismuth quadruple therapy (standard dose PPI twice daily, met- } \\
\text { ronidazole } 500 \mathrm{mg} \text { three times daily, bismuth } 120 \mathrm{mg} \text { and tetracycline } 500 \mathrm{mg} \text { four } \\
\text { times daily for } 10 \text { to } 14 \text { days) are similar to } 14 \text { days standard triple therapy, } 10 \text { days } \\
\text { concomitant therapy, and } 10 \text { days sequential therapy. However, because of its high } \\
\text { adverse effects and potential use as second-line therapy, it can be recommended to } \\
\text { be used as first-line therapy if other first-line therapy options are not available. }\end{array}$ & Moderate & Weak \\
\hline \multirow[t]{3}{*}{ Salvage therapy } & $\begin{array}{l}\text { 9. After failure of standard triple therapy, a bismuths quadruple therapy (PPI, bismuth, } \\
\text { tetracycline, and metronidazole) for } 14 \text { days is recommended as a second-line therapy. }\end{array}$ & High & Strong \\
\hline & $\begin{array}{l}\text { 10. After failure of non-bismuth quadruple therapy (sequential or concomitant therapy), a } \\
\text { bismuth quadruple therapy is recommended as a second-line therapy. }\end{array}$ & Very low & Strong \\
\hline & $\begin{array}{l}\text { 11. After failure of bismuth quadruple therapy as } 1 \text { st-line or } 2 \text { nd-line therapy lafter failed } \\
\text { standard triple or non-bismuth quadruple therapyl, a levofloxacin triple therapy is } \\
\text { suggested as a salvage therapy. }\end{array}$ & Very low & Weak \\
\hline
\end{tabular}

$\mathrm{PPI}$, proton pump inhibitor; PCR, polymerase chain reaction. 
studies with $H$. pylori eradication therapy combined with iron supplementation to treat the IDA. However, these studies were heterogeneous because of confounders including age (children or adolescents vs adults), sex and different study setting in terms of different definition of IDA or outcomes (quantitative assessment of ferritin or hemoglobin or qualitative assessment, such as recovery from anemia). Meta-analysis including children, adolescents, or adults showed significant increase of ferritin after the eradication, not hemoglobin. Meta-analysis of seven RCTs showed increased ferritin, standardized mean difference of 0.53 ( $95 \%$ CI, 0.21 to 0.85 ), but not hemoglobin, standardized mean difference of 0.36 (95\% CI, -0.07 to 0.78$)$. ${ }^{27}$ However, there were limited studies which showed the efficacy of $H$. pylori eradication in adult population. Nonrandomized comparative study in adults with IDA showed the additional effect of $H$. pylori eradication on iron supplement in adult patients with IDA and $H$. pylori-positive chronic gastritis. ${ }^{28}$ In a prospective observational study, H. pylori infection was correlated with low serum ferritin level and after eradication, serum ferritin increased; however, the sample size was too small. ${ }^{29}$ In this study, serum ferritin in premenopausal women was significantly lower than that of postmenopausal women, but not different in men. In other observational studies with adult patients with IDA, IDA was resolved after $38.1 \%$ of eradication of $H$. pylori-eradicated patients $(32 / 84)$. This was more frequent in men and postmenopausal women compared with premenopausal women $(75 \%$ vs $23 \%, \mathrm{p}<0.01) .{ }^{30}$ Despite the very low level of evidence, it was decided as a "weak recommendation" because short-term treatment of $H$. pylori infection has the potential for long-term benefits and low risk for serious harm.

\section{2) After ER of gastric adenoma}

Is $H$. pylori eradication helpful to prevent metachronous recurrence after ER of gastric adenoma?

Statement 2. H. pylori eradication can be recommended after ER for $H$. pylori-positive gastric adenoma to prevent metachronous recurrence.

Grade of recommendation: weak

Level of evidence: low

Experts' opinions: completely agree (60.0\%), mostly agree $(20.0 \%)$, partially agree $(20.0 \%)$, mostly disagree $(0 \%)$, completely disagree $(0 \%)$, not sure $(0 \%)$

Many studies have reported that the incidence rate of metachronous cancer decreased with $H$. pylori eradication after ER of early gastric cancer (EGC). ${ }^{31-33}$ Thus, H. pylori should be eradicated to prevent metachronous recurrence after ER of EGC. However, there was no definite guideline about $H$. pylori eradication after ER of gastric adenoma. Until now, there were two RCTs about $H$. pylori eradication to prevent metachronous gastric cancer after ER of gastric tumors including EGC and adenoma (Supplementary Table 1$){ }^{31-33}$ Three retrospective studies about $H$. pylori eradication after ER of gastric adenoma were reported. ${ }^{34-36}$ All of them were conducted in Korea. According to studies, the incidence of metachronous recurrence was lower in $H$. pylori-eradicated group than non-eradicated group $(3.24 \%$ vs $4.87 \%^{33}$; $7.69 \%$ vs $14.29 \%^{31} ; 7.76 \%$ vs $10.80 \%^{34} ; 8.20 \%$ vs $19.44 \%^{35} ; 4.71 \%$ vs $11.36 \%^{36}$ ). When meta-analysis included five studies, the effect of $H$. pylori on prevention of metachronous recurrence after ER of gastric adenoma was statistically significant (OR, $0.55 ; 95 \% \mathrm{CI}, 0.34$ to 0.92 ) (Fig. 2).

According to studies, $H$. pylori eradication is helpful to prevent metachronous recurrence after ER of gastric ad-

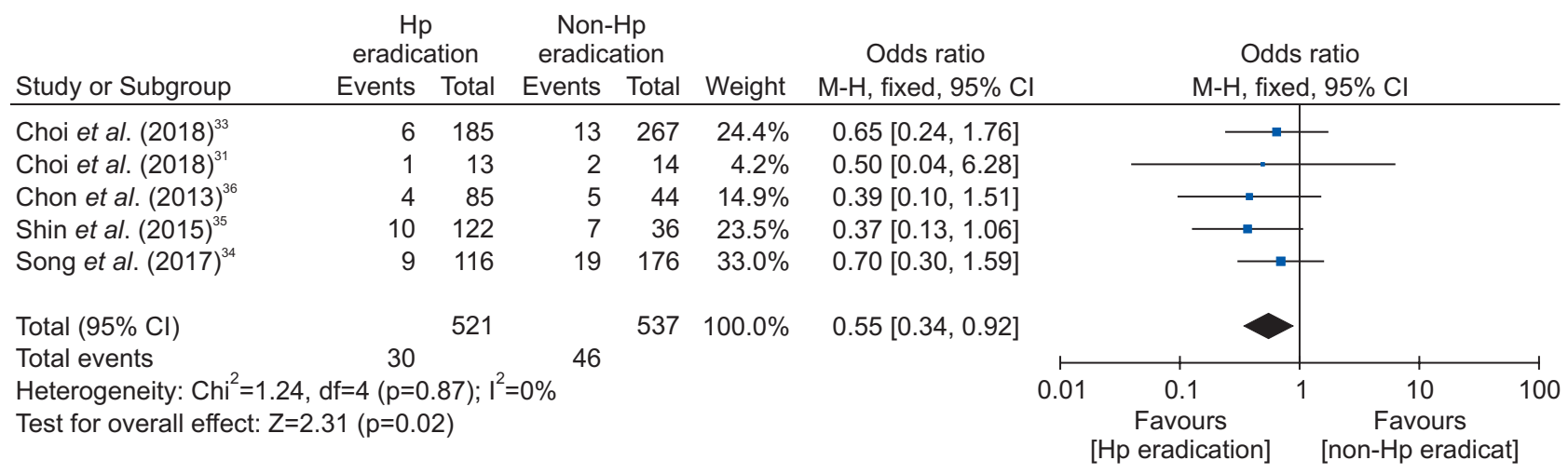

Fig. 2. Comparison of the occurrence of metachronous gastric cancer after endoscopic resection of gastric adenoma between Helicobacter pylori ( $\mathrm{Hp}$ ) eradication and placebo treatment.

$\mathrm{M}-\mathrm{H}$, Mantel-Haenszel test; $\mathrm{Cl}$, confidence interval. 
enoma. Therefore, $H$. pylori eradication is indicated after ER for $H$. pylori-positive gastric adenoma. However, RCT focused on gastric adenoma is required to support this recommendation.

\section{3) Functional dyspepsia}

Is $H$. pylori eradication helpful in symptom relief in patients with functional dyspepsia?

Statement 3. H. pylori eradication can be recommended for long-term improvement of dyspeptic symptoms in patients with functional dyspepsia.

Grade of recommendation: weak

Level of evidence: high

Experts' opinions: completely agree (43.3\%), mostly agree $(26.7 \%)$, partially agree $(23.4 \%)$, mostly disagree (3.3\%), completely disagree (3.3\%), not sure (0\%)

In the meta-analysis of RCTs, when $H$. pylori was eradicated in dyspeptic patients, the symptom improvement was not significant in the short-term ( 3 months) followup, but symptoms were significantly improved in the longterm (6 to 12 months) follow-up. ${ }^{37,38}$ Based on these results, the Maastricht V guidelines in Europe and the U.S. and Canadian guidelines strongly recommend the eradication of $H$. pylori as the first-line treatment for dyspepsia. ${ }^{11,39}$

In the present guideline, 18 RCTs from January 1997 to December 2017 were selected and meta-analysis was conducted to evaluate the long-term effects of $H$. pylori eradication in patients with dyspepsia (Supplementary Table 2). ${ }^{40-57}$ In a meta-analysis of 4,672 patients from 18 RCTs, the risk ratio (RR) of persistence of dyspeptic symptoms in the control group was 1.18 (95\% CI, 1.07 to 1.31 ) compared with the eradication group. Although statistically significant, the number of patients needed for treatment (number needed to treat, NNT) was 14, and heterogeneity among studies was moderate $\left(\mathrm{I}^{2}=34 \%\right)$ (Supplementary Fig. 1$).^{58}$

Because of the heterogeneity among the studies, subgroup analysis was performed by region to analyze five RCTs from the Asian regions and 13 RCTs from outside Asian regions. Meta-analysis from RCTs from outside Asia regions showed significant improvement of dyspeptic symptoms in eradication group (RR, 1.22; 95\% CI, 1.08 to 1.38; $\left.\mathrm{I}^{2}=33 \%\right)$. However, because of analysis of RCTs from Asia, the effect of eradication on improvement of dyspeptic symptoms was not significant (RR, 1.10; 95\% CI, 0.92 to $\left.1.31 ; \mathrm{I}^{2}=32 \%\right)$.

In summary, eradication of $H$. pylori improved dyspeptic symptoms significantly, however, the clinical effect was not large due to the improvement of symptoms in 1 of 14 treated patients $(\mathrm{NNT}=14)$ and the result of subgroup analysis of RCTs conducted in Asia was not statistically significant. The prevalence of $H$. pylori in Korea is estimated to be $54 \%$ (95\% CI, $50.1 \%$ to $57.8 \%$ ) according to a study that estimates the prevalence of $H$. pylori worldwide. ${ }^{59}$ In areas with high prevalence of $H$. pylori, costs, adverse effects associated with eradication therapy, the risk of emergence of resistance strains, and re-infection are thought to be higher than those of low prevalence regions. Therefore, in the present guideline, it was decided to make weak recommendations despite the high level of evidence for $H$. pylori eradication in patients with functional dyspepsia. The RCTs, including cost-effectiveness analysis of eradication therapy in patients with functional dyspepsia in areas with high prevalence of $H$. pylori, including in Korea, are likely to be needed.

\section{4) Chronic atrophic gastritis and IM}

Is $H$. pylori eradication effective to prevent gastric cancer in the presence of chronic atrophic gastritis and IM?

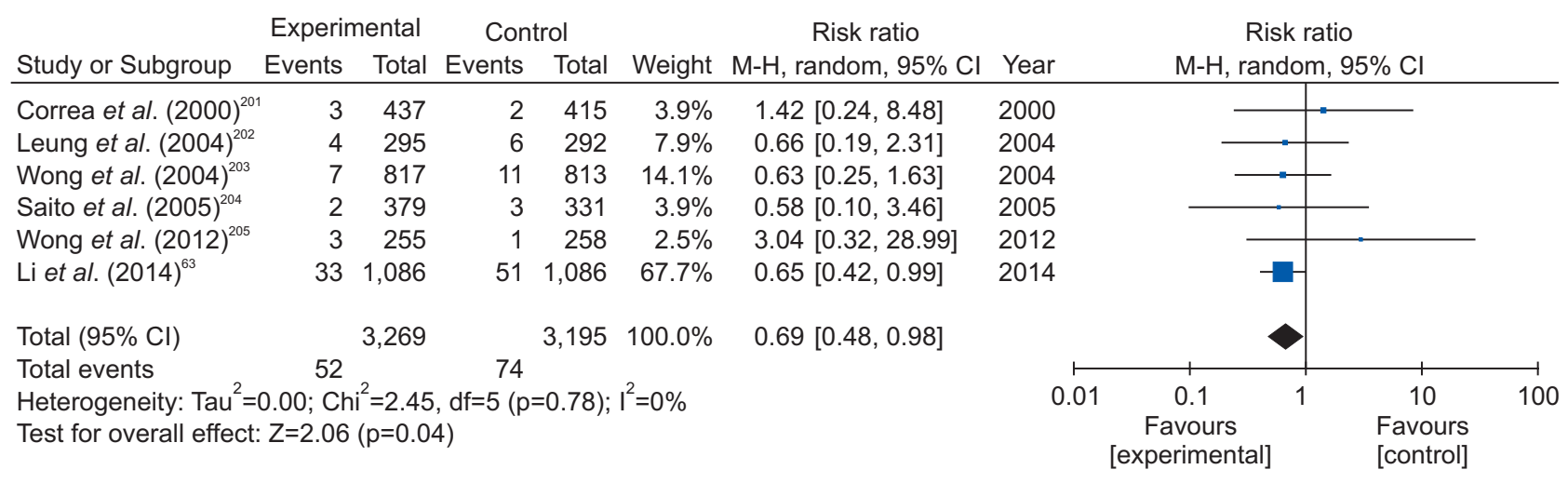

Fig. 3. Forest plot of studies reporting the impact of Helicobacter pylori eradication on gastric cancer from studies involving the general population. $\mathrm{M}-\mathrm{H}$, Mantel-Haenszel test; $\mathrm{Cl}$, confidence interval. 
$H$. pylori eradication can reduce the risk of gastric cancer development. However, it is controversial whether the eradication can be beneficial in individuals with pre-neoplastic lesions including chronic atrophic gastritis (CAG) and IM.

Recently published two meta-analyses showed that individuals with non-atrophic or CAG benefited from eradication in reducing the risk of gastric cancer, whereas individuals with IM and/or dysplasia did not. ${ }^{60,61}$ The effect of $H$. pylori eradication can be affected by the degree of mucosal atrophy. $H$. pylori eradication can be more beneficial to subjects with mild mucosal atrophy than those with extensive atrophic gastritis. ${ }^{62}$ Maastricht $\mathrm{V}$ guideline recommended that the risk for gastric cancer can be reduced more effectively by eradicating $H$. pylori before atrophy and IM develop. ${ }^{11}$

However, the two meta-analyses included the studies that evaluated the effect of $H$. pylori eradication on the occurrence of metachronous gastric cancers after ER of EGC, as well as the studies in the general population. The effect of $H$. pylori eradication may be different between in the general population and in the high-risk group. Moreover, a population-based cohort study in China, which was not included in the previous meta-analyses, showed that $H$. pylori eradication can benefit individuals with IM and/or dysplasia at baseline, suggesting $H$. pylori eradication can benefit an entire population regardless of the baseline gastric histopathology. ${ }^{63}$

When the meta-analysis was performed using the RCTs in the general population only, $H$. pylori eradication significantly reduced the incidence of gastric cancer, as in previous studies (Fig. 3). In a subgroup analysis that included only subjects with CAG or IM, eradication had no effect on the prevention of gastric cancer, and two studies involving subjects without CAG and IM did not demonstrate significant gastric cancer prevention effect (Supplementary Fig. 2 ). However, in the latter case, the number of incidences of gastric cancer were small, and there were limitations in drawing an accurate conclusion. In expert consensus based on these analyses, only $48.0 \%$ agreed in the first e-mail questionnaire, and only $63.3 \%$ agreed in the second faceto-face meeting. In other words, there is no firm evidences or expert agreement to recommend eradication of $H$. pylori in subjects with CAG or IM, so re-discussion is needed after more researches have been accumulated. The indications for $H$. pylori eradication treatment presented above are summarized in Table 3.

\section{H. pylori eradication therapy}

\section{1) First-line therapy}

In patients undergoing $H$. pylori eradication for the first time, one of the following four regimens can be used: 14-day standard triple therapy, non-bismuth quadruple therapy, 7-day standard triple therapy after clarithromycin resistance test, and bismuth quadruple therapy.

\section{(1) Standard triple therapy}

Can standard triple therapy be one of the first-line therapy for $H$. pylori eradication?

Statement 4. Standard triple therapy (standard dose PPI, amoxicillin $1 \mathrm{~g}$, and clarithromycin $500 \mathrm{mg}$ twice daily) for 14 days is recommended for first-line regimen.

Grade of recommendation: strong

Level of evidence: moderate

Experts' opinions: completely agree (27.0\%), mostly agree $(50.0 \%)$, partially agree $(14.0 \%)$, mostly disagree (9.0\%), completely disagree $(0 \%)$, not sure $(0 \%)$

To make appropriate choice of first-line regimen, we need to consider the regional resistance pattern and eradication rate. Many factors, such as compliance, gastric acidity, and bacterial loads are related to the efficacy of triple therapy. However, the eradication rate of standard triple therapy is mainly influenced by clarithromycin resistance. Clarithromycin resistance has increased during the last 10 years in Korea, and the resistance rate of clarithromycin in Korea is reported to be $17.8 \%-31.0 \%{ }^{2,14}$ The geographic distribution of clarithromycin resistance is highly variable. According to the recently published nationwide antibiotics resistance mapping study in Korea, the resistance rate of clarithromycin was less than $15 \%$ in the Seoul and Chungcheong areas and over 15\% in other parts of Korea. ${ }^{2}$ These

Table 3. Indications for the Eradication of Helicobacter pylori

\begin{tabular}{|c|c|c|}
\hline Existing indication & Added indication & Admissive indication \\
\hline Peptic ulcer disease & After endoscopic resection of gastric adenoma & Atrophic gastritis/intestinal metaplasia \\
\hline Marginal zone B-cell lymphoma & Iron deficiency anemia & \\
\hline \multicolumn{3}{|c|}{ After endoscopic resection of early gastric cancer } \\
\hline \multicolumn{3}{|l|}{ Family history of gastric cancer } \\
\hline \multicolumn{3}{|l|}{ Functional dyspepsia } \\
\hline \multicolumn{3}{|c|}{ Long-term low-dose aspirin user with a history of peptic ulcer } \\
\hline Idiopathic thrombocytopenic purpura & & \\
\hline
\end{tabular}


results suggest that clarithromycin triple therapy is still acceptable as a first-line treatment in some parts of Korea.

To be eligible for a first-line treatment of $H$. pylori eradication therapy, the regimen must show at least $80 \%$ to $85 \%$ of the eradication rate. ${ }^{8,64}$ To find an eradication rate for standard triple therapy in Korea, we searched and selected all RCTs conducted in Korea which have used clarithromycin triple therapy since 2007. Twenty-six studies were included in meta-analysis (Supplementary Table 3). ${ }^{65-90}$ Overall pooled eradication rates of standard triple therapy derived from these studies were $71.6 \%$ (95\% CI, 69.9\% to $73.3 \%$ ) in intention-to-treat (ITT) analysis and 79.6\% (95\% CI, $76.6 \%$ to $82.2 \%$ ) in per protocol (PP) analysis (Fig. 4). Studies were divided into 2007-2011 and 2012-2016. Pooled eradication rates of 2007-2011 and 2012-2016 were $72.3 \%$ (95\% CI, $71.2 \%$ to $74.4 \%$ ) and $70.3 \%$ (95\% CI, $68.4 \%$ to $72.1 \%$ ) in ITT analysis, respectively. The pooled eradication rate of standard triple therapy in 2012-2016 was on the decline compared with 2007-2011. The pooled eradication rate of standard triple therapy was inadequate to be used as a first-line treatment. This result was similar to that of prospective RCT conducted in 2018 by Korean College of Helicobacter and Upper Gastrointestinal Research. ${ }^{91}$ Therefore, to use the standard triple therapy as a first-line treatment, it is necessary to consider introducing a clarithromycin resistance test or extending the treatment duration.

Regarding duration of standard triple therapy, we ana-

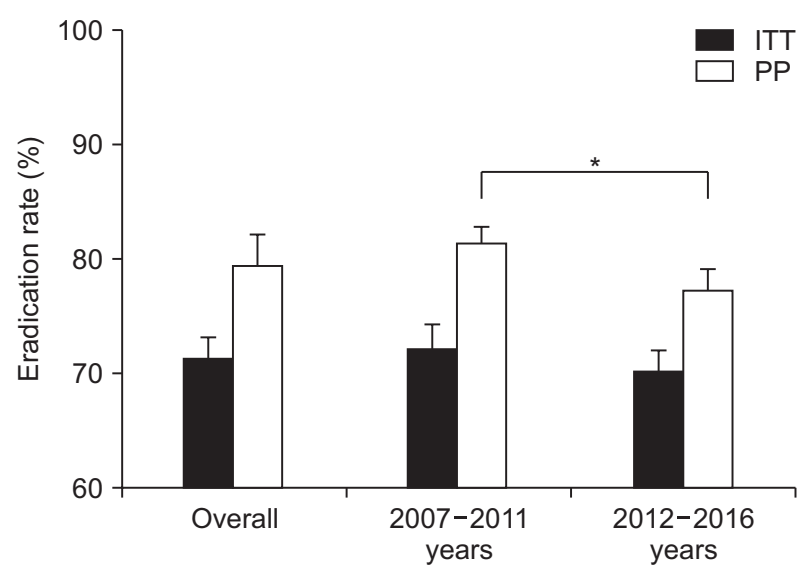

Fig. 4. Time trends of pooled Helicobacter pylori eradication rates of standard triple therapy from randomized controlled trials performed in Korea (by years). The overall eradication rates of standard triple therapy were $71.6 \%$ (95\% confidence interval [CI], $69.9 \%$ to $73.3 \%$ ) in ITT analysis and $79.6 \%(95 \% \mathrm{Cl}, 76.6 \%$ to $82.2 \%)$ in PP analysis. The eradication rates from 2007 to 2011 were $72.3 \%$ (95\% Cl, $71.2 \%$ to $74.4 \%)$ in ITT analysis and $81.5 \%(95 \% \mathrm{Cl}, 79.9 \%$ to $82.9 \%)$ in PP analysis. The eradication rates from 2012 to 2016 were $70.3 \%$ (95\% Cl, $68.4 \%$ to $72.1 \%)$ in ITT analysis and $77.4 \%(95 \% \mathrm{Cl}, 75.6 \%$ to $79.2 \%)$ in PP analysis.

ITT, intention-to-treat; PP, per protocol. * ${ }^{*}<0.01$. lyzed the pooled eradication rate of 7-day, 10-day, and 14day therapy. The pooled eradication rate of 7-day standard triple therapy was $70.0 \%$ (95\% CI, $68.5 \%$ to $71.4 \%)$ and that of 10 -day therapy was $73.7 \%$ (95\% CI, $69.8 \%$ to $77.2 \%)$ in ITT analysis. The pooled eradication rate (ITT) of 14day therapy was $78.1 \%$ (95\% CI, $75.2 \%$ to $80.7 \%$ ) which was significantly higher than those of 7-day and 10-day therapy ( $<0.01$ for both duration) (Supplementary Fig. 3). Eradication rates between the 7-day and 10-day therapy were not significantly different. A network meta-analysis published in 2017 that analyzed 34 RCTs since 2005 also showed similar results. ${ }^{92}$ The pooled eradication rates (ITT) of 7-day, 10-day, and 14-day standard triple therapy were $71.1 \%$ (95\% CI, $68.3 \%$ to $73.7 \%$ ), $67.0 \%$ (95\% CI, $60.0 \%$ to $73.4 \%$ ), and $76.4 \%$ (95\% CI, $73.3 \%$ to $79.2 \%$ ), respectively. In addition, according to a national multicenter study published in 2019, the eradication rates of 7-day standard triple therapy were $63.9 \%$ in ITT analysis and $71.4 \%$ in PP analysis. ${ }^{91}$

Based on the above analysis and the available evidences, a 14-day therapy is recommended when considering standard triple therapy as a first-line treatment without clarithromycin resistance test.

(2) Non-bismuth quadruple therapy

(a) Sequential therapy

Can sequential therapy be one of the first-line therapy of $H$. pylori eradication?

Statement 5. Sequential therapy (standard dose PPI, amoxicillin $1 \mathrm{~g}$ twice daily for 5 days followed by standard dose PPI, clarithromycin $500 \mathrm{mg}$, and metronidazole $500 \mathrm{mg}$ twice daily for 5 days) can be one of firstline therapies for $H$. pylori eradication.

Grade of recommendation: strong

Level of evidence: high

Experts' opinions: completely agree (31.0\%), mostly agree $(39.0 \%)$, partially agree $(9.0 \%)$, mostly disagree $(21.0 \%)$, completely disagree $(0 \%)$, not sure $(0 \%)$

In recent guidelines, non-bismuth quadruple therapy, sequential or concomitant treatment, or bismuth quadruple therapy is recommended as the first-line treatment in regions where clarithromycin resistance is more than $15 \%{ }^{11,93}$ Non-bismuth quadruple therapy uses amoxicillin, clarithromycin, and metronidazole simultaneously with PPI, but each method has different duration of use for individual antibiotic. Sequential therapy is a method of using PPI and amoxicillin for the first 5 days, and then administering PPI, clarithromycin and metronidazole for 5 days from 6 to 10 days. 
A meta-analysis of 24 RCTs $(n=5,070)$ was conducted to confirm the effect on sequential therapy as the first-line treatment (Supplementary Table 4). ${ }^{75,77-80,90,94-111}$ Twenty RCTs compared comparing standard triple therapy, two RCTs comparing bismuth quadruple therapy, and two RCTs comparing hybrid therapy were included. RCTs comparing sequential therapy with concomitant therapy (CT) are described in the CT section.

i) Sequential therapy versus standard triple therapy

Twenty studies compared the eradication rate between sequential therapy and conventional therapy. In all, 3,224 and 3,152 patients were treated with sequential and standard triple therapies, respectively. The eradication rates of sequential therapy and overall standard triple therapy were $84.1 \%$ and $74.9 \%$ in the ITT analysis, respectively. The rates of sequential therapy and overall standard triple therapy were $85.9 \%$ and $77.3 \%$ in the PP analysis, respectively. The pooled RR of the ITT eradication rates (sequential therapy vs standard triple therapy) was 1.37 with the fixed effects model (95\% CI, 1.21 to 1.54) (Fig. 5), while the pooled RR of the PP eradication rates was 1.60 with the fixed effects model (95\% CI, 1.40 to 1.83 ) (Supplementary Fig. 4).

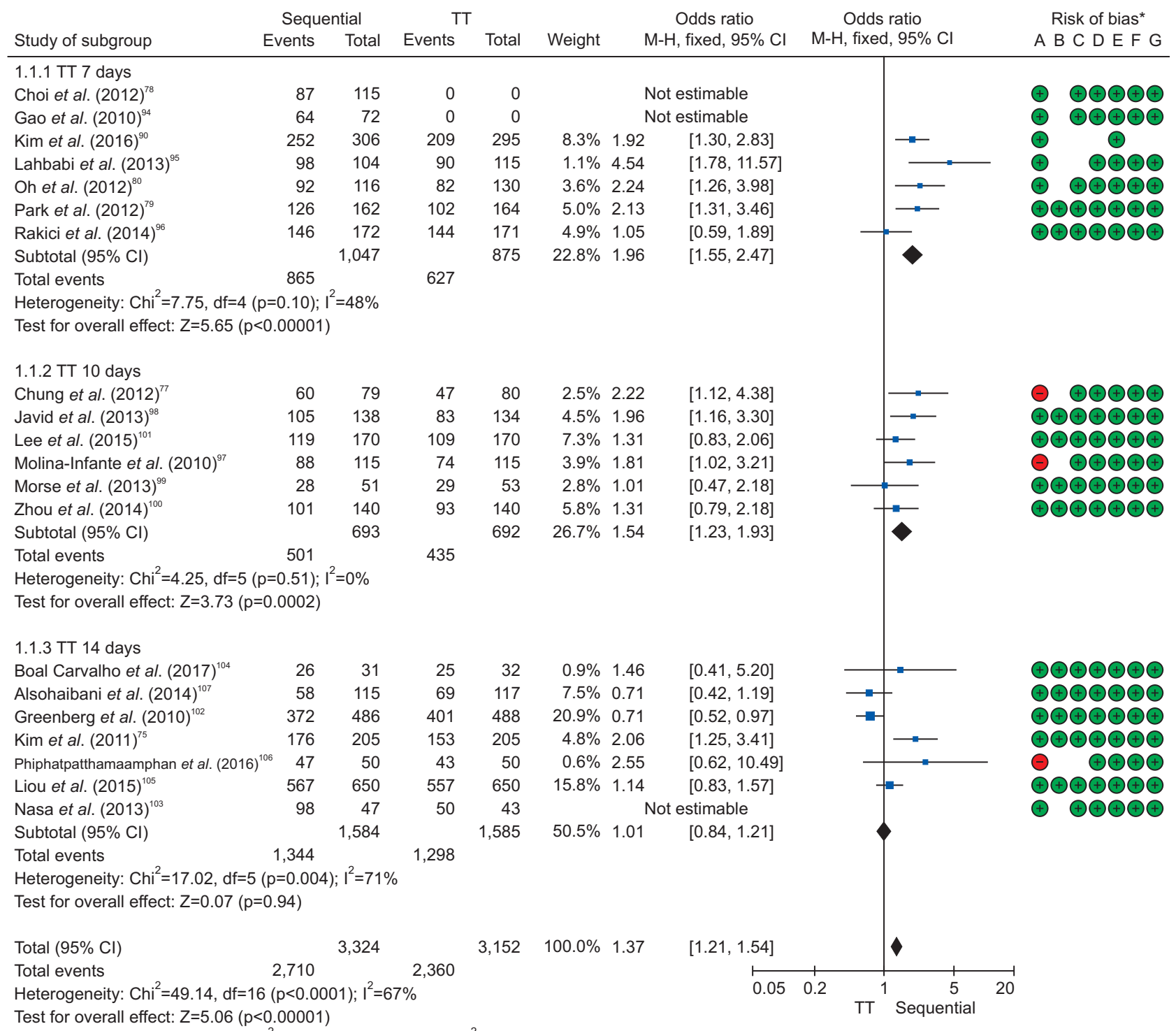

Fig. 5. Comparison between 10-day sequential therapy and standard triple therapy (TT) according to the treatment duration of TT in intention-totreat analysis.

$\mathrm{M}-\mathrm{H}$, Mantel-Haenszel test; $\mathrm{Cl}$, confidence interval. *Risk of bias: $\mathrm{A}$, random sequence generation (selection bias); $\mathrm{B}$, allocation concealment (selection bias); $C$, blinding of participants and personnel (performance bias); D, blinding of outcome assessment (detection bias); $E$, incomplete outcome data (attrition bias); F, selective reporting (reporting bias); G, other bias. 
ii) Sequential therapy versus bismuth quadruple therapy

In the meta-analysis of two RCTs comparing 10-day sequential therapy with bismuth quadruple therapy, the eradication rates of the two therapies were not significantly different (RR, 0.79; $95 \%$ CI, 0.47 to 1.32 in ITT analysis; RR, 0.63; 95\% CI, 0.27 to 1.49 in PP analysis). However, there was a limitation that the number of patients included was small and local studies were not included (Supplementary Fig. 5).

iii) Sequential therapy versus hybrid therapy

In a meta-analysis of two RCT studies comparing 10day sequential therapy with hybrid therapy, the 10-day sequential therapy showed a lower eradication rate than hybrid therapy (RR, 0.36 ; $95 \%$ CI, 0.23 to 0.58 in ITT analysis; RR, 0.18 ; $95 \%$ CI, 0.10 to 0.35 in PP analysis) (Supplementary Fig. 6). However, there was a limitation that the number of patients included was small and no local studies were included.

In summary, the eradication rate of 10-day sequential therapy as a first-line treatment was higher than that of standard triple therapy, and in the subgroup analysis, sequential therapy showed a higher eradication rate than the 7-day and 10-day standard triple therapy but a comparable eradication rate with the 14-day standard triple therapy. The comparative analysis of bismuth quadruple therapy and hybrid therapy was difficult to conclude due to the small number of RCTs. Therefore, as clarithromycin resistance increases in Korea, 10-day sequential therapy is recommended when first-line treatment is considered without clarithromycin resistance testing.

\section{(b) Concomitant therapy}

Can CT be one of the first-line therapy of H. pylori eradication?
Statement 6. CT (standard dose PPI, clarithromycin $500 \mathrm{mg}$, amoxicillin $1 \mathrm{~g}$, and metronidazole $500 \mathrm{mg}$ twice daily for 10 days) is recommended as a first-line treatment.

Grade of recommendation: strong

Level of evidence: high

Experts' opinions: completely agree (66.7\%), mostly agree (13.3\%), partially agree (13.4\%), mostly disagree (3.3\%), completely disagree $(3.3 \%)$, not sure $(0 \%)$

$\mathrm{CT}$, in which amoxicillin, clarithromycin, and metronidazole are administered simultaneously for 10 days is one of the non-bismuth quadruple therapy (concomitant, sequential, and hybrid therapy) used to overcome the decreased eradication rates of standard triple therapy. To investigate the efficacy of CT as first-line treatment of $H$. pylori eradication, we selected RCTs including CT. Short term treatment of CT (5-day CT or 7-day CT) were excluded. A total of 26 RCTs were finally eligible in this analysis and the characteristics of each study are shown in Supplementary Table $5{ }^{84,89,109,112-131}$ A total of 21 studies of 10-day CT, six studies of 14-day CT and one RCT of both 10-day CT and 14-day CT were included. The eradication rate for 10 -day CT was $85 \%$ for ITT analysis and $91 \%$ for PP analysis, and the rate for 14-day CT was $86 \%$ for ITT analysis and $94 \%$ for PP analysis, which was higher than that of standard triple therapy. There was no difference in eradication rate according to the duration in the subgroup analysis. From the analysis including studies conducted in Korea only, the eradication rates of 10-day CT were $84 \%$ in ITT analysis and $92 \%$ in PP analysis, and those of 14day CT were $79 \%$ in ITT analysis and $94 \%$ in PP analysis; there was no difference in eradication rate according to the administration duration (Supplementary Table 6).

CT for 10 days showed a slightly higher eradication rate

ST

10-day CT (10-day, 14-day) Risk ratio Risk ratio

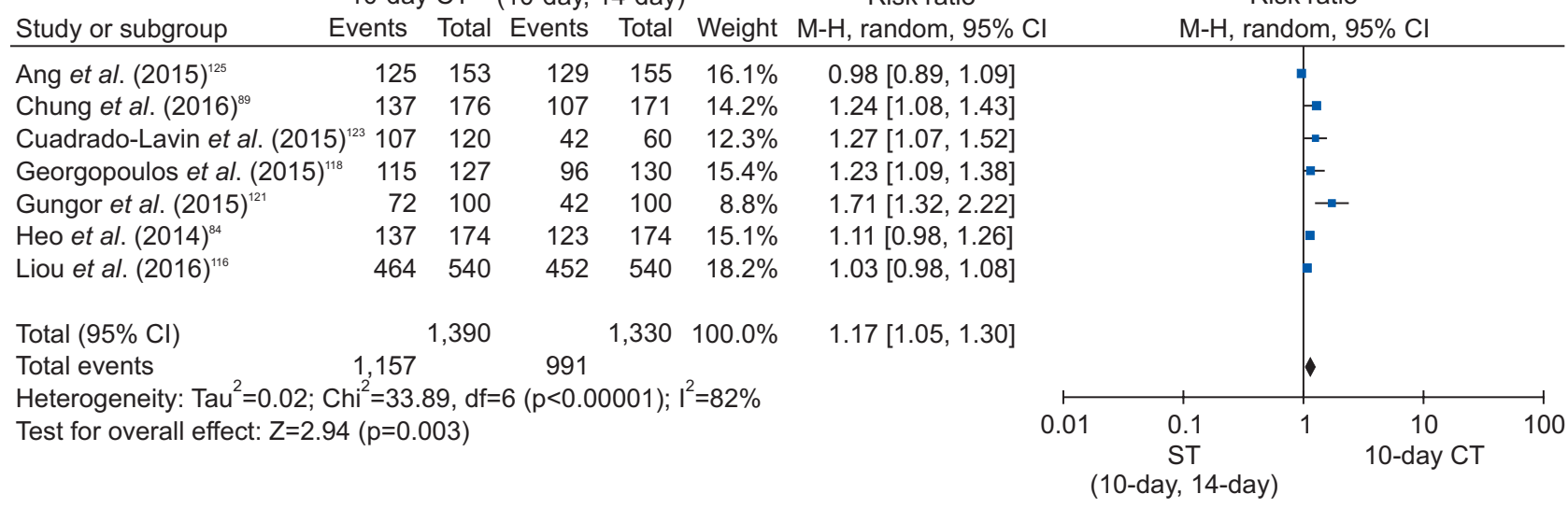

Fig. 6. Comparison between 10-day concomitant therapy (CT) and 10-day/14-day standard triple therapy in intention-to-treat analysis. ST, standard triple therapy; $\mathrm{M}-\mathrm{H}$, Mantel-Haenszel test; $\mathrm{Cl}$, confidence interval. 
compared to sequential therapy and a $17 \%$ higher eradication rate compared to 10-day/14-day standard triple therapy, and the evidence level was high. There was no difference in eradication rate between bismuth quadruple therapy and hybrid therapy, and the levels of evidence were evaluated as moderate and high, respectively.

Through the systematic search, 21 RCTs comparing 10day CT with other regimens were selected. Eight RCTs compared 10-day CT with 10-day/14-day standard triple therapy. The eradication rate of 10 -day CT was significantly higher than that of 10-day/14-day standard triple therapy (RR, 1.17; 95\% CI, 1.05 to 1.30 in ITT analysis; RR, 1.15; 95\% CI, 1.06 to 1.25 in PP analysis) (Fig. 6).

In 13 RCTs, 10-day CT and 10-day sequential therapy were compared. The eradication rate of 10-day CT was significantly higher than that of the 10-day sequential therapy, but the difference seems to be small (RR, 1.04; 95\% CI, 1.00 to 1.08 in ITT analysis; RR, 1.04; 95\%, CI 1.01 to 1.07 in PP analysis) (Supplementary Fig. 7). The eradication rate of CT was slightly higher than that of sequential treatment, which is thought to be because CT is more effective than sequential treatment if it is resistant only to either clarithromycin or metronidazole. In fact, in case of clarithromycin resistance, CT had a higher eradication rate compared to sequential therapy. ${ }^{132,133}$ In the case of metronidazole-resistant but, not clarithromycin-resistant, $\mathrm{CT}$ also showed higher eradication rate than sequential therapy. ${ }^{132,134}$

In six RCTs, 10-day CT and 10-day/14-day of bismuth quadruple therapy were compared. The eradication rate of 10-day CT was not significantly different from that of bismuth quadruple therapy (RR, 1.05; 95\% CI, 0.96 to 1.15 in ITT analysis; RR, 1.01; 95\% CI, 0.97 to 1.06 in PP analysis) (Supplementary Fig. 8). In two RCTs, 10-day CT and hybrid therapy were compared, and there was no difference between the two groups (RR, 0.99; 95\% CI, 0.93 to 1.05 in ITT analysis). The eradication rates of 14-day CT and 10-day/14-day sequential treatments were compared in three RCTs. The eradication rate of 14-day CT did not differ from that of 10-day/14-day sequential therapy in the ITT analysis (76\% vs $79 \%$ ), but in the PP analysis, the eradication rate of 14-day CT was slightly higher than that of sequential therapy ( $89 \%$ vs $82 \%$ ). In two RCTs, 14 -day CT and 14-day standard triple therapy were compared, and 14-day CT showed significantly higher eradication rate than 14-day standard triple therapy ( $88 \%$ vs $79 \%$ in ITT analysis; $94 \%$ vs $82 \%$ PP analysis). In two RCTs, $14-$ day CT and hybrid therapy were compared, and 14-day CT showed slightly higher eradication rate than hybrid therapy ( $91 \%$ vs $85 \%$, p=0.05 in ITT analysis; $96 \%$ vs $92 \%, p=0.07$ in $\mathrm{PP}$ analysis).
In summary, the eradication rate of 10 -day $\mathrm{CT}$ as first-line treatment was significantly higher than that of 10-day/14-day standard triple therapy but slightly higher than that of sequential therapy and similar to those of bismuth quadruple therapy and hybrid therapy. The eradication rate of 14-day CT was significantly higher compared to 14-day standard triple therapy in both PP and ITT analysis, and 10-day/14-day sequential therapy in the PP analysis. The eradication rates of 10-day CT and 14-day CT were similar. Therefore, if first-line treatment is considered without resistance test, 10-day CT is recommended.

\section{(3) Standard triple therapy based on clarithromycin resis- tance test}

Does clarithromycin resistance test improve the eradication rate of standard triple therapy?

Statement 7. Clarithromycin resistance test by PCR or sequencing is recommended when a 7-day standard triple therapy is considered as a first-line treatment.

Grade of recommendation: strong

Level of evidence: low

Experts' opinions: completely agree (76.7\%), mostly agree $(6.6 \%)$, partially agree (16.6\%), mostly disagree (0\%), completely disagree (0\%), not sure $(0 \%)$

The eradication rate of empirical standard triple therapy (PPI + amoxicillin + clarithromycin) has been declined to about $70 \%$ through the last decades in Korea. ${ }^{135,136}$ The 2013 revised Korean guideline recommended this therapy as one of primary regimens for $H$. pylori eradication, even though experts' complete agreement rate of this strategy was only $53.6 \%{ }^{8}$ Maastricht $\mathrm{V}$ guideline recommended that clarithromycin-based triple therapy without susceptibility testing should be abandoned when the regional clarithromycin resistance rate is more than $15 \% .{ }^{11}$ Considering the decreasing and sub-optimal eradication rate of this empirical therapy and high resistance rate of clarithromycin in Korea, new strategies are desperate for improving eradication rate of $H$. pylori.

Although clarithromycin susceptibility test by $H$. pylori culture is the best method for appropriate selection of $H$. pylori eradication regimens, ${ }^{137,138}$ it is very difficult to apply culture-based results to clinical practice because of slow growth of $H$. pylori and demanding culture conditions. On the contrary, tailored therapy after molecular testing using polymerase chain reaction (PCR)-kits or sequencing methods detecting $23 \mathrm{~S}$ ribosomal RNA point mutations related to clarithromycin resistance is one of easily applicable methods.

In the large case-control study $(\mathrm{n}=1,232)$, the patients 
who had the $\mathrm{A} 2142 \mathrm{G}$ and $\mathrm{A} 2143 \mathrm{G}$ point mutations associated with clarithromycin resistance based on dual priming oligonucleotide-based multiplex PCR were treated with PPI + amoxicillin + metronidazole (PAM) for 7 days, and the patients without clarithromycin resistance were treated with standard triple therapy for 7 days (tailored therapy). The eradication rate of $H$. pylori in the tailored therapy group was $80.7 \%$ (176/218), which was significantly higher than that in the empirical 7-day standard triple therapy $(69.5 \%, 214 / 308 ; \mathrm{p}<0.01)$ or PAM $(71.1 \%, 219 / 308 ; \mathrm{p}=0.01)$ control groups in ITT analysis. ${ }^{82}$ In addition, the recent two case-control studies reported that 7-day tailored therapy with bismuth quadruple therapy, PAM, or standard triple therapy had higher eradication rates than those of empirical 7 -day standard triple therapy ( $91.8 \%$ vs $72.1 \%$; $94.3 \%$ vs $76.5 \%$, respectively) in PP analysis. ${ }^{20,21}$ Importantly, the costs for a successful eradication with tailored therapy could be similar or superior to those of empirical 14-day standard triple therapy. ${ }^{21}$
(4) Bismuth quadruple therapy

Can bismuth quadruple therapy be one of the first-line therapy of $H$. pylori eradication?

Statement 8. Eradication rates of bismuth quadruple therapy (standard dose PPI twice daily, metronidazole $500 \mathrm{mg}$ three times daily, bismuth $120 \mathrm{mg}$ and tetracycline $500 \mathrm{mg}$ four times daily for 10 to 14 days) are similar to 14 days standard triple therapy, 10 days CT, and 10 days sequential therapy. However, because of its high adverse effects and potential use as second-line therapy, it can be recommended to be used as first-line therapy if other first-line therapy options are not available.

Grade of recommendation: weak

Level of evidence: moderate

Experts' opinions: completely agree (50.0\%), mostly agree $(33.4 \%)$, partially agree $(10.0 \%)$, mostly disagree $(3.3 \%)$, completely disagree $(3.3 \%)$, not sure $(0 \%)$

A

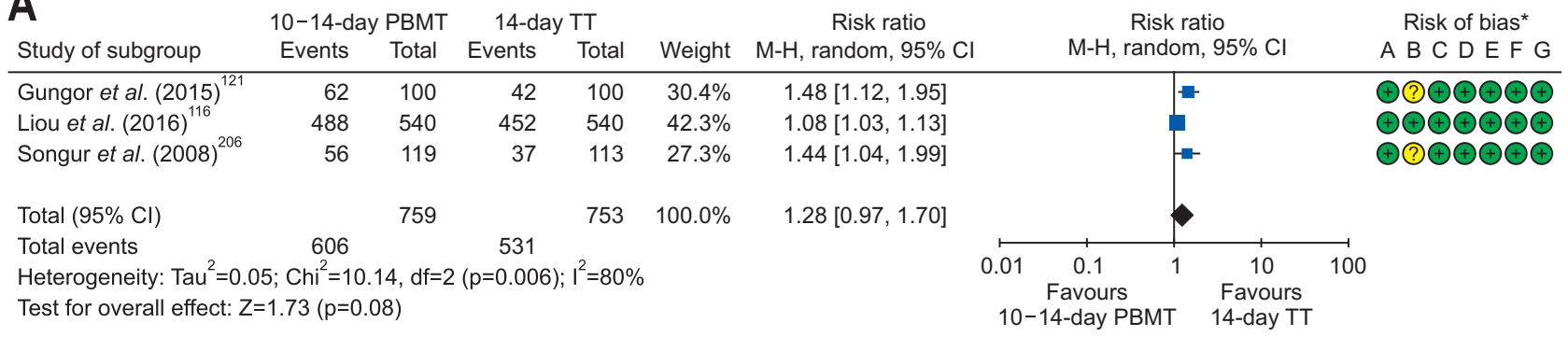

B

\begin{tabular}{|c|c|c|c|c|c|c|c|c|c|c|c|}
\hline Study of subgroup & $\begin{array}{l}10-14-d a \\
\text { Events }\end{array}$ & PBMT & $\begin{array}{l}\text { 10-day } \\
\text { Fyents }\end{array}$ & SQT & Weiaht & $\begin{array}{c}\text { Risk ratio } \\
\text { M-H. random } 95 \% \mathrm{Cl}\end{array}$ & & $\mathrm{M}-\mathrm{H}, \mathrm{Ri}$ & $\begin{array}{l}\text { sk ratio } \\
\text { dom, } 95 \% \mathrm{Cl}\end{array}$ & & $\begin{array}{l}\text { Risk of bias* } \\
A B C D E F G\end{array}$ \\
\hline Gungor et al. $(2015)^{121}$ & 62 & 100 & 71 & 100 & $34.6 \%$ & $0.87[0.72,1.06]$ & & & 는 & & 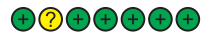 \\
\hline Kefeli et al. $(2016)^{109}$ & 114 & 130 & 113 & 130 & $65.4 \%$ & $1.01[0.92,1.11]$ & & & th & & 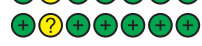 \\
\hline Total $(95 \% \mathrm{Cl})$ & & 230 & & 230 & $100.0 \%$ & $0.96[0.83,1.12]$ & & & 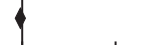 & & \\
\hline $\begin{array}{l}\text { Total events } \\
\text { Heterogeneity: } \text { Tau }^{2}=0 \text {. } \\
\text { Test for overall effect: } Z\end{array}$ & $\begin{array}{r}176 \\
1 ; \mathrm{Chi}^{2}=2 . \\
=0.54(p=0\end{array}$ & 8, df= & $\begin{array}{r}184 \\
=0.15)\end{array}$ & $2 \%$ & & & $\begin{array}{r}0.01 \\
10-\end{array}$ & $\begin{array}{c}0.1 \\
\text { Favours } \\
\text { 1-day PBI }\end{array}$ & $\begin{array}{cc}1 & 10 \\
T & \text { Favours } \\
\text { 10-day SC }\end{array}$ & 100 & \\
\hline
\end{tabular}

C

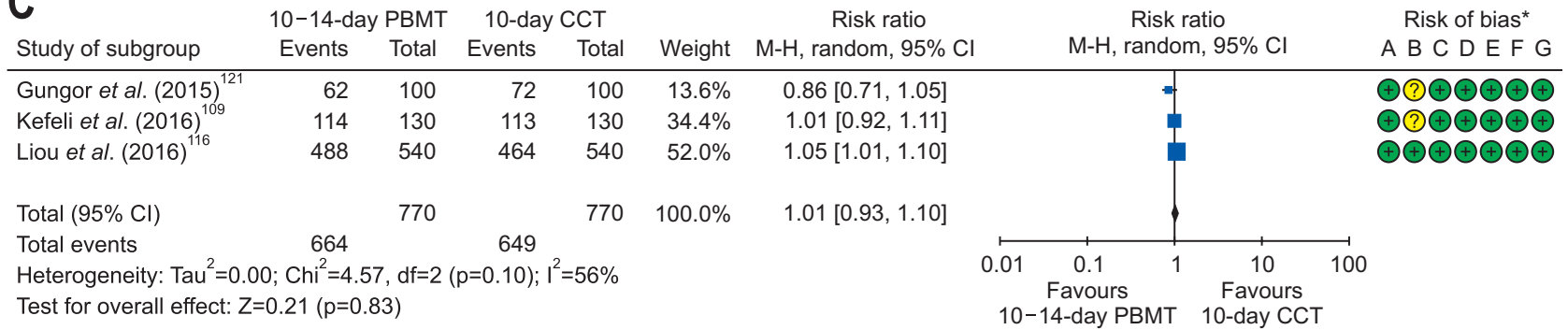

Fig. 7. Comparison of the eradication rate of PBMT as first-line therapy in intention-to-treat analysis. (A) 10-day/14-day PBMT versus 14-day TT; (B) 10-day/14-day PBMT versus 10-day SQT; and (C) 10-day/14-day PBMT versus 10-day CCT.

$\mathrm{M}-\mathrm{H}$, Mantel-Haenszel test; $\mathrm{Cl}$, confidence interval; PBMT, bismuth quadruple therapy; TT, standard triple therapy; SQT, sequential therapy; CCT, concomitant therapy. *Risk of bias: A, random sequence generation (selection bias); B, allocation concealment (selection bias); C, blinding of participants and personnel (performance bias); D, blinding of outcome assessment (detection bias); $E$, incomplete outcome data (attrition bias); $F$, selective reporting (reporting bias); $G$, other bias. 
Established guidelines recommended that bismuth quadruple or non-bismuth quadruple therapies are suitable for the first-line H. pylori eradication therapy in high clarithromycin resistance areas. ${ }^{11,139}$

In two network meta-analysis studies of the RCTs, the efficacy of bismuth-containing quadruple therapy varied depending on the type of eradication regimens and duration of therapies. ${ }^{140,141}$ We performed meta-analysis including nine RCTs from January 2008 to July 2018 investigating the efficacy and safety of bismuth quadruple therapy for the first-line H. pylori eradication (Supplementary Table 7). Pooled eradication rates of bismuth quadruple therapy by ITT analysis and PP analysis were $84.5 \%$ (95\% CI, $74.9 \%$ to $90.9 \%$ ) and $90.6 \%$ (95\% CI, $82.8 \%$ to $95.1 \%)$, respectively. However, there was no statistically significant difference of ITT eradication rates in 10-14 days bismuth quadruple therapy compared to 14 days standard triple therapy (RR, 1.28; 95\% CI, 0.97 to 1.70 ) (Fig. 7A), 10 days sequential therapy (RR, 0.96 ; 95\% CI, 0.83 to 1.12 ) (Fig. 7B), and 10 days $\mathrm{CT}$ (RR, 1.01; 95\% CI, 0.93 to 1.10) (Fig. 7C). In addition, there was no statistically significant difference of PP eradication rates in 10-14 days bismuth quadruple therapy compared to 14 days standard triple therapy (RR, 1.37; 95\% CI, 0.95 to 1.99), 10 days sequential therapy (RR, 0.99; 95\% CI, 0.93 to 1.05 ), and 10 days CT (RR, 1.01; 95\% CI, 0.95 to 1.07$)$. Heterogeneity among studies was generally moderate, and we should interpret these results with caution due to small numbers of the current meta-analysis.

In terms of adverse events, bismuth quadruple therapy was significantly higher than other eradication therapies (RR, 1.72; 95\% CI, 1.23 to 2.40) (Supplementary Fig. 9). However, considerable heterogeneity was shown among studies $\left(\mathrm{I}^{2}=92 \%\right)$.

Bismuth quadruple therapy is regarded as a promising treatment for patients with allergy to penicillin as well as $H$. pylori with dual resistance. ${ }^{139}$ Therefore, it may be one of the attractive options for $H$. pylori eradication. Unfortunately, there are few rescue therapies for $H$. pylori eradication, and high adverse events of bismuth quadruple therapy cannot be ignored in clinical practice. Thus, bismuth quadruple therapy can be first-line treatment for $H$. pylori eradication when other first-line options are unavailable, due to its high adverse events rate and bismuth quadruple therapy is a widely used rescue therapy for other regimens.

Further well-designed studies are required to confirm the efficacy of bismuth quadruple therapy for fist-line $H$. pylori eradication in Korea. Additionally, regarding the bismuth dosage, bismuth subcitrate $\left(\mathrm{DeNol}^{\mathbb{R}}\right) 300 \mathrm{mg}$ contains elemental bismuth $120 \mathrm{mg}$. Therefore, physicians can prescribe bismuth subcitrate $300 \mathrm{mg}$ four times daily in clinical practice.

\section{2) Salvage therapy}

What is the recommended salvage regimen after failure of previous $H$. pylori eradication therapy?

In the last decade, the efficacy of PPI, clarithromycin, and amoxicillin triple therapy has decreased mainly due to clarithromycin resistance. ${ }^{142,143}$ As a result, it has become a common situation in clinical practice to choose a salvage regimen after failure of one or more eradication attempts. Moreover, the selection of a rescue regimen may be more complicated with the emergence of alternative first-line treatments such as sequential or concomitant therapies.

In the systematic literature review, there were $36 \mathrm{RCTs}$ that compared different combinations of antibiotics, different durations of a regimen, or different PPIs as salvage therapy after one or more eradication failures between 2008 and 2017 (Supplementary Table 8): ${ }^{144-179} 24$ RCTs evaluated second-line regimens, five evaluated third-line regimens, five compared different durations of a regimen, and two compared different doses or kinds of PPIs. Most studies for second-line regimens were conducted after failure of clarithromycin-based triple therapy; there was no RCT that evaluated second-line regimens after failure of non-bismuth or bismuth quadruple therapy, and there was no RCT that evaluated third-line regimen after failure of first-line clarithromycin-based triple therapy followed by second-line bismuth quadruple therapy. Meta-analyses were conducted and there were more than three RCTs. The recommendations on the salvage regimen were primarily based on those RCTs and their meta-analyses. However, when no suitable trial was found, the most relevant cohort studies, published systematic reviews of cohort studies, and RCTs published before 2008 were referenced for the recommendations. All eradication rates presented below are from ITT analyses. The evidences which were included in the meta-analysis of regimens for salvage therapy are summarized in the Supplementary Table 9.

Statement 9. After failure of standard triple therapy, a bismuths quadruple therapy (PPI, bismuth, tetracycline, and metronidazole) for 14 days is recommended as a second-line therapy.

Grade of recommendation: strong

Level of evidence: high

Experts' opinions: completely agree (90.0\%), mostly agree (6.7\%), partially agree (3.3\%), mostly disagree $(0 \%)$, completely disagree $(0 \%)$, not sure $(0 \%)$

In the 2013 revised Korean guidelines, bismuth quadruple therapy (PPI, bismuth, tetracycline, and metronidazole) for 7-14 days was recommended. The systematic review conducted for the present guidelines identified 15 
RCTs which compared 31 treatment arms as second-line treatment after failure of first-line PPI-clarithromycinamoxicillin triple therapy. ${ }^{144,149,153,158-160,162-165,171-173,176,179}$ Of those, nine studies adopted bismuth quadruple therapy, ${ }^{153,158,159,162,164,172,173,176,179}$ and eight studies adopted levofloxacin triple therapy (PPI, amoxicillin, and levofloxacin):; $;^{144,149,162,163,165,172,173,179}$ of those, four studies compared bismuth quadruple therapy and levofloxacin triple therapy directly. ${ }^{162,172,173,179}$

Bismuth quadruple therapy showed pooled eradication rate of $75.5 \%$ (95\% CI, $71.6 \%$ to $79.1 \%$ ) in the metaanalysis of the nine studies (Fig. 8). Regarding the treatment duration, four studies treated for 7 days, two for 10 days, and three for 14 days. Because 10-day and 14-day regimens showed similar efficacy, subgroup analysis was conducted to compare 7-day versus 10 - to 14 -day bismuth quadruple therapy. In result, 10- to 14-day therapy showed significantly higher eradication rates (pooled eradication rate, $81.6 \%$; $95 \% \mathrm{CI}, 76.9 \%$ to $\left.85.6 \%, \mathrm{I}^{2}=29.6 \%\right)$ than 7-day therapy (pooled eradication rate, $68.4 \%$; $95 \% \mathrm{CI}$, 53.0 to $73.5 \%$; $\left.\mathrm{I}^{2}=73.8 \%\right)(\mathrm{p}<0.01)$. The systematic review also identified three RCTs comparing 14-day versus 7-day bismuth quadruple therapies. Meta-analysis of these RCTs also showed a significant eradication rate with 14-day regimen than 7-day regimen (risk difference [RD], 0.09; 95\% CI, 0.02 to $0.15 ; \mathrm{p}<0.01$ ).

Levofloxacin triple therapy showed pooled eradication rate of $73.1 \%$ (95\% CI, $68.4 \%$ to $77.3 \%$ ) in the meta-analysis of the eight studies (Fig. 9). In the subgroup analysis comparing treatment duration, the 10- to 14-day regimen

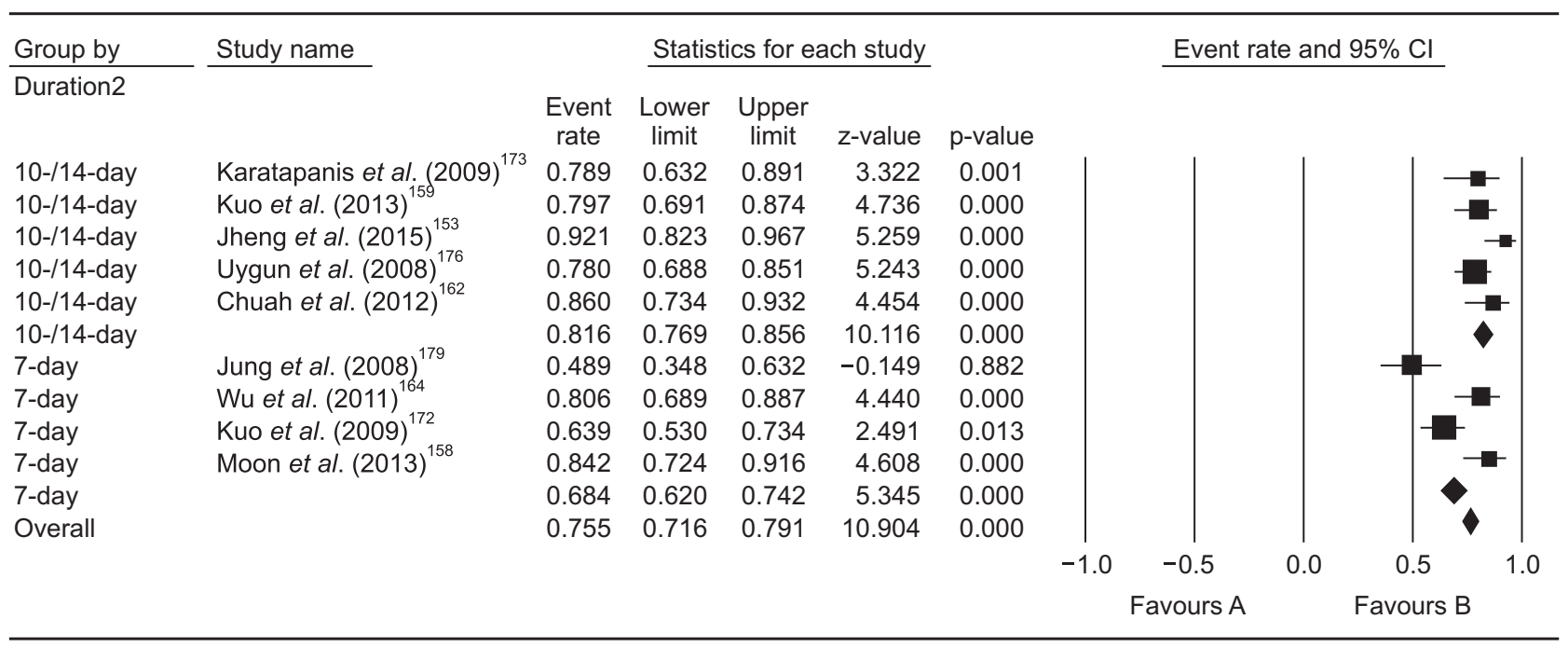

Fig. 8. Meta-analysis of nine studies comparing bismuth quadruple therapy with other regimens after failure of first-line standard triple therapy. The pooled eradication rate of bismuth quadruple therapy as a second-line therapy was $75.5 \%$ (95\% confidence interval [Cl], $71.6 \%$ to $79.1 \%$ ).

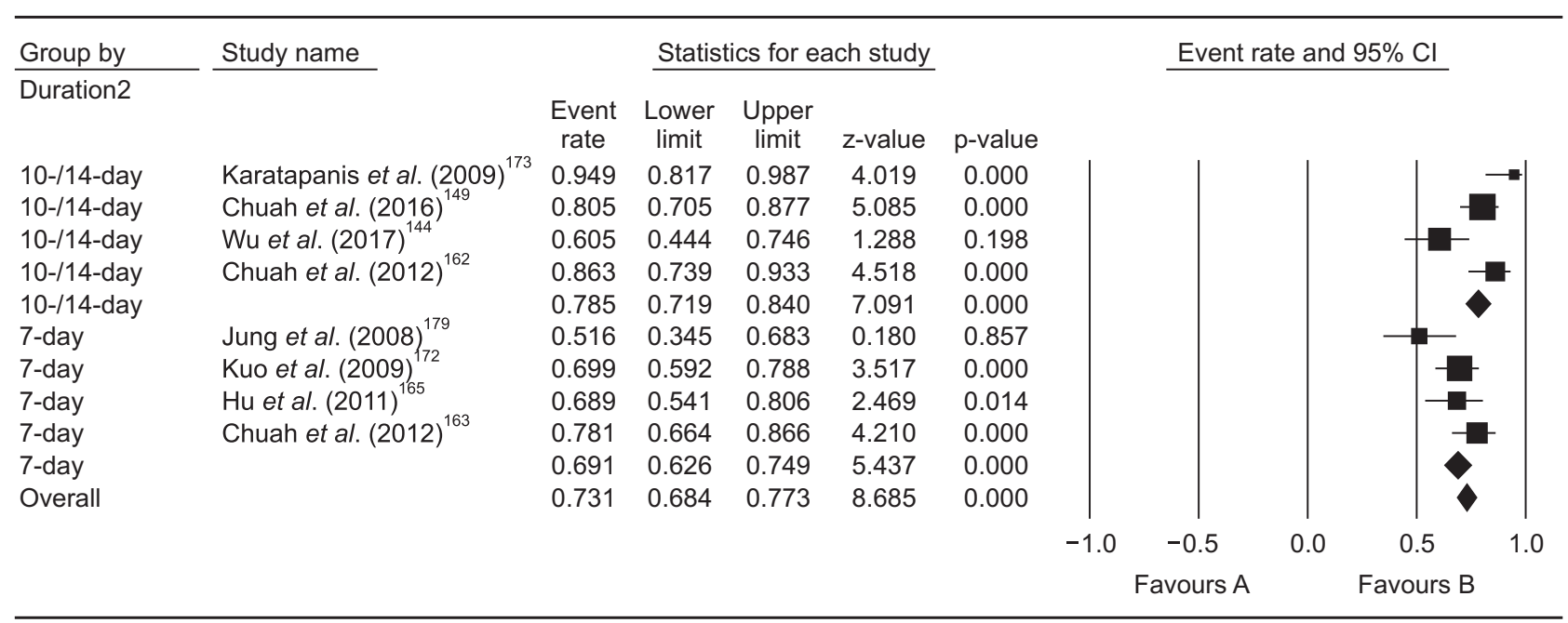

Fig. 9. Meta-analysis of eight studies that compared levofloxacin triple therapy with other regimens after failure of first-line line clarithromycin triple therapy. The pooled eradication rate of levofloxacin triple therapy as a second-line therapy was $73.1 \%$ (95\% confidence interval [Cl], $68.4 \%$ to $77.3 \%$ ). 
in four studies showed a significantly higher eradication rate $(78.5 \%$; $95 \% \mathrm{CI}, 71.9 \%$ to $84.0 \%)$ than 7 -day regimen in four studies (69.1\%; 95\% CI, $61.6 \%$ to $74.9 \%$; $\mathrm{p}=0.04$ ). One factorial RCT reported 10-day therapy showed significantly higher eradication rate with 7-day therapy (87.5\% vs $67.5 \%, p<0.01) .{ }^{174}$ Meanwhile, there was no significant difference in the dose of levofloxacin between $500 \mathrm{mg}$ daily and $1,000 \mathrm{mg}$ daily in this study $(\mathrm{p}=1.00)$.

There was no significant difference in the eradication rates between bismuth quadruple therapy and levofloxacin triple therapy in the meta-analysis of four RCTs. There were non-significant contradictory trends favoring levofloxacin triple therapy in ITT analysis (bismuth quadruple vs levofloxacin triple: $\mathrm{RD},-0.06$; $95 \% \mathrm{CI},-0.14$ to $0.02 ; \mathrm{p}=0.16$ ) but favoring bismuth quadruple therapy in PP analysis (RD, 0.02 ; $95 \% \mathrm{CI},-0.05$ to $0.10 ; \mathrm{p}=0.58$ ) (Supplementary Fig. 10). These results may be because of low tolerability of bismuth quadruple therapy. In two systematic reviews published in 2006, 10-day levofloxacin triple therapy showed superior efficacy compared to 7-day bismuth quadruple therapy. ${ }^{180,181}$ In our meta-analysis, two regimens were treated for the same duration ( 7 days vs 7 days, 10 days vs 10 days, or 14 days vs 14 days). Thus, it can be suggested that bismuth quadruple therapy and levofloxacin triple therapy may have similar efficacy when the two treatments are administered for the same duration.

A major limitation of levofloxacin triple therapy is that efficacy of the regimen is substantially reduced in the presence of levofloxacin resistance. ${ }^{162}$ In Korea, the resistance rate for levofloxacin in H. pylori strains has been increasing rapidly as high as $28.1 \% .{ }^{14,182,183}$ Very recently, the nationwide antibiotic resistance profile of $H$. pylori in Korean population was reported. ${ }^{2}$ According to this report, resistance rate against levofloxacin was $37.0 \%$. Thus, bismuth quadruple therapy would be favored over levofloxacin triple therapy in Korea. However, it should also be noted that resistance rate against metronidazole was also as high as $29.5 \%$ in the same study. Because resistance to metronidazole can be overcome with increased duration and dose, 14-day course would be preferred to 10- to 14-day course for bismuth quadruple therapy as a salvage regimen in Korea. ${ }^{184}$ Therefore, bismuth quadruple therapy for 14 days is recommended as a second-line therapy after failure of standard triple therapy.

Statement 10. After failure of non-bismuth quadruple therapy (sequential or concomitant therapy), a bismuth quadruple therapy is recommended as a second-line therapy.

Grade of recommendation: strong

Level of evidence: very low
Experts' opinions: completely agree (60.0\%), mostly agree $(30.0 \%)$, partially agree $(6.7 \%)$, mostly disagree $(3.3 \%)$, completely disagree $(0 \%)$, not sure $(0 \%)$

There was no RCT comparing salvage regimens after failure of first-line non-bismuth quadruple therapy. There was a meta-analysis of cohort studies in which most studies included were a levofloxacin triple regimen. ${ }^{185}$ In this study, the pooled eradication rate of levofloxacin triple therapy from five studies including 86 patients was $81 \%$ (95\% CI, $71 \%$ to $91 \%$; $I^{2}=28 \%$ ). Another meta-analysis conducted in Maastricht V guidelines showed 81\% (six studies; 95\% CI, $73 \%$ to $90 \% ; \mathrm{I}^{2}=19 \%$ ) after failure of sequential therapy and $78 \%$ (three studies; $95 \%$ CI, $58 \%$ to $97 \% ; I^{2}=67 \%$ ) after failure of $\mathrm{CT}^{11}$ However, these results may not be directly applicable to Korean population because of high levofloxacin resistance rates as previously discussed. ${ }^{2,14,182,183}$

Bismuth quadruple therapy showed eradication rate of $84 \%$ ( $95 \% \mathrm{CI}, 63 \%$ to $106 \% ; \mathrm{I}^{2}=56 \%$ ) in the meta-analysis conducted in Maastricht V. ${ }^{11}$ However, the analysis included only two cohort studies of similar sample sizes with each other. One of them was a study conducted in Korea where 14-day bismuth quadruple therapy achieved successful eradication in 10 of 14 patients.

Therefore, bismuth quadruple therapy is recommended as a second-line therapy after failure of first-line nonbismuth quadruple therapy based on currently available evidences. However, more data is required to support this recommendation.

Statement 11. After failure of bismuth quadruple therapy as first-line or second-line therapy (after failed standard triple or non-bismuth quadruple therapy), a levofloxacin triple therapy is suggested as a salvage therapy.

Grade of recommendation: weak

Level of evidence: very low

Experts' opinions: completely agree (40.0\%), mostly agree $(30.0 \%)$, partially agree $(13.3 \%)$, mostly disagree $(16.7 \%)$, completely disagree $(0 \%)$, not sure $(0 \%)$

The most common situation in which bismuth quadruple therapy fails in Korea is failures as a second-line regimen after failure of first-line standard triple therapy. This approach was recommended by previous Korean guidelines 2013 and Maastricht IV guidelines. ${ }^{8,186}$ The scenario in which second-line bismuth quadruple therapy fails after failure of first-line non-bismuth quadruple therapy is also expected to be a more common situation. In these cases, it is not recommended to use clarithromycin again in the third-line regimen. ${ }^{184}$ It would be also inappropriate to use 
clarithromycin after failure of first-line bismuth quadruple therapy because this regimen had been chosen as first-line when clarithromycin resistance was suspected. ${ }^{8}$ Treatment regimen may be decided based on antibiotics susceptibility tests, either by culture, PCR, or sequencing analysis. Generally, it is recommended not to use clarithromycin, fluoroquinolone, and rifabutin again in the presence of resistance to respective drugs, while amoxicillin and metronidazole may be re-used. ${ }^{184}$ However, it is noteworthy that benefits of susceptibility-guided therapy over empirical regimen was evident only in the first-line treatment, not in the second-line setting in a recent systematic review. ${ }^{138}$ Neither was it in the third-line treatment in a recent RCT. ${ }^{187}$ The first-line and salvage treatment regimens and algorithms for $H$. pylori treatment combined with the regimens are summarized in Table 4 and Fig. 10, respectively.

\section{(1) Levofloxacin triple therapy}

There was no RCT comparing rescue options after failure of bismuth quadruple therapy either as first-line or second-line regimen. In 2012, Gisbert reported on the efficacy of third-line PPI-amoxicillin-levofloxacin triple

Table 4. Regimen of Recommended Therapies for Helicobacter pylori Infection

\begin{tabular}{|c|c|c|c|}
\hline Regimen & Drugs & Frequency & Duration (day) \\
\hline Standard triple therapy & $\begin{array}{l}\text { PPI (standard dose) } \\
\text { Clarithromycin }(500 \mathrm{mg} \text { ) } \\
\text { Amoxicillin (1 g) }\end{array}$ & bid & $7-14$ \\
\hline Bismuth quadruple & $\begin{array}{l}\text { PPI (standard dose) } \\
\text { Bismuth subcitrate }(120 \mathrm{mg}) \\
\text { Tetracycline }(500 \mathrm{mg}) \\
\text { Metronidazole }(500 \mathrm{mg})\end{array}$ & $\begin{array}{l}\text { bid } \\
\text { qid } \\
\text { qid } \\
\text { tid }\end{array}$ & $10-14$ \\
\hline Sequential & $\begin{array}{l}\text { PPI (standard dose) + amoxicillin (1 g) then, PPI + } \\
\text { clarithromycin + metronidazole }\end{array}$ & $\begin{array}{l}\text { bid } \\
\text { bid }\end{array}$ & $\begin{array}{l}5 \\
5\end{array}$ \\
\hline Concomitant & $\begin{array}{l}\text { PPI (standard dose) } \\
\text { Clarithromycin (500 mg) } \\
\text { Amoxicillin }(1 \mathrm{~g}) \\
\text { Metronidazole }(500 \mathrm{mg})\end{array}$ & bid & 10 \\
\hline Hybrid & $\begin{array}{l}\text { PPI (standard dose) + amoxicillin (1 g) then, PPI + } \\
\text { amoxicillin + clarithromycin + metronidazole }\end{array}$ & $\begin{array}{l}\text { bid } \\
\text { bid }\end{array}$ & $\begin{array}{l}7 \\
7\end{array}$ \\
\hline Levofloxacin triple & $\begin{array}{l}\text { PPI (standard dose) } \\
\text { Levofloxacin ( } 500 \mathrm{mg} \text { or } 250 \mathrm{mg} \text { ) } \\
\text { Amoxicillin (1 g) }\end{array}$ & $\begin{array}{l}\text { bid } \\
\text { qd (500 mg), bid (250 mg) } \\
\text { bid }\end{array}$ & $10-14$ \\
\hline
\end{tabular}

PPI, proton pump inhibitor; qd, once a day; bid, twice per day; tid, three times per day; qid, four times per day.

\begin{tabular}{|c|c|c|c|c|c|c|}
\hline \multirow{3}{*}{ 1st-line } & \multicolumn{3}{|c|}{ Empirical treatment (without CM resistance test) } & \multicolumn{3}{|c|}{ Clarithromycin resistance test } \\
\hline & \multirow[b]{2}{*}{$\begin{array}{l}\text { PAC } 14 \text { days } \\
\text { (PPI-amoxicillin } \\
\text {-clarithromycin) }\end{array}$} & \multirow{2}{*}{$\begin{array}{l}\text { Sequential or } \\
\text { concomitant } \\
\text { therapy } 10 \text { days } \\
\text { (PPl-amoxicillin } \\
\text {-clarithromycin- } \\
\text { metronidazole) }\end{array}$} & \multirow{2}{*}{$\begin{array}{l}\text { Bismuth quadruple } \\
\text { therapy } 10-14 \text { days } \\
\text { (PPI-bismuth- } \\
\text { tetracycline- } \\
\text { metronidazole) }\end{array}$} & Sensitive & \multicolumn{2}{|c|}{ Resistant } \\
\hline & & & & PAC 7 days & $\begin{array}{l}\text { PAM }^{*} \\
7 \text { days }\end{array}$ & \\
\hline 2nd-line & \multicolumn{6}{|c|}{$\begin{array}{l}\text { Bismuth quadruple therapy } \\
\text { (PPI-bismuth-tetracycline-metronidazole) }\end{array}$} \\
\hline $\begin{array}{l}\text { 2nd-/3rd- } \\
\text { line }\end{array}$ & \multicolumn{6}{|c|}{$\begin{array}{l}\text { Levofloxacin triple therapy (PPI-amoxicillin-levofloxacin) and others: } \\
\text { fluoroquinolone triple/quadruple, rifabutin containing therapy, high dose dual, concomitant therapy }\end{array}$} \\
\hline
\end{tabular}

Fig. 10. Proposed algorithm for Helicobacter pylori treatment in Korea. Bismuth quadruple therapy as a first-line therapy is dotted because it is less preferred than other regimens.

$\mathrm{CM}$, clarithromycin; PPI, proton pump inhibitor. *The PAM regimen consists of PPI, amoxicillin, and metronidazole. 
therapy in a systematic review of six cohort studies including 350 patients and a cohort study including 200 of their own patients. ${ }^{188}$ This was updated in Maastricht V as 501 patients in five studies resulting in pooled eradication rate of $70.0 \%$ (95\% CI, $62.4 \%$ to $76.6 \%$; $\left.\mathrm{I}^{2}=58.5 \%\right) .{ }^{11}$ A Korean study reported retrospective data from 14 medical centers in 2017, in which 110 patients received levofloxacin thirdline therapy, 88 adhered to the treatment protocol, and 63 achieved successful eradication (62 after PPI-amoxicillinlevofloxacin and one after PPI-amoxicillin-clarithromycinlevofloxacin). The estimated eradication rate with thirdline levofloxacin triple therapy was $56.9 \%(62 / 109){ }^{189}$ Although previously failed first- and second-line regimens were not specified in this study, this low eradication rate may have been due to the high levofloxacin resistance rate in Korea. ${ }^{2,14,182,183}$ Therefore, a levofloxacin triple therapy is suggested as a salvage therapy after failure of first-line or second-line bismuth quadruple therapy. However, the efficacy of this regimen may be lower than observed in the systematic review as indicated in the Korean retrospective study.

\section{(2) Triple therapy containing other fluoroquinolones}

Three Japanese RCTs evaluated fluoroquinolone based triple therapy after first-line PPI-amoxicillin-clarithromycin and second-line PPI-amoxicillin-metronidazole failure: ${ }^{147,157,178}$ the sitafloxacin-PPI-amoxicillin regimen showed an eradication rate of 70.0\% (49/70; 95\% CI, 59.0\% to $81.0 \%)$ after 7 -day therapy and $81.0 \%(51 / 63 ; 95 \% \mathrm{CI}$, $71.0 \%$ to $90.9 \%$ ) after 10 -day therapy, ${ }^{147,157}$ while gatifloxacin-PPI-amoxicillin 7-day therapy was administered to only eight patients with six eradication successes $(75 \%){ }^{178}$ In European prospective cohort study, moxifloxacin-PPIamoxicillin 14 -day therapy showed $82.4 \%$ eradication rate (206/250; 95\% CI, $77.0 \%$ to $87.0 \%)$ after failure of first-line clarithromycin triple or non-bismuth quadruple therapy. ${ }^{190}$ However, in a Korean retrospective cohort study, the same regimen with 7-14 days showed successful eradiation in only $67.9 \%$ (95\% CI, 51.5-84.9\%) after failure of first-line bismuth quadruple therapy. ${ }^{191}$ Thus, evidences are limited for triple therapy containing other fluoroquinolones after failure of bismuth quadruple therapy because the abovementioned studies are highly heterogeneous regarding the design and previous regimens. The potential cross-resistance among fluoroquinolones may further limit the usage of other fluoroquinolones as alterative to levofloxacin in rescue therapy. ${ }^{183}$

\section{(3) Fluoroquinolone quadruple therapy}

There was no RCT evaluating fluoroquinolone quadruple therapy after failure of bismuth quadruple therapy.
However, eight RCTs compared 10 arms of various fluoroquinolone quadruple regimens with other regimens after failure of first-line triple therapy. ${ }^{14}$

The levofloxacin-bismuth quadruple regimen (levofloxacin, bismuth, PPI, and amoxicillin) was suggested as an "encouraging salvage strategy" in patients failing previous bismuth quadruple therapy in Maastricht $\mathrm{V}$ guidelines because of synergistic effects between bismuth and levofloxacin to overcome antibiotics resistance. ${ }^{11}$ This regimen was evaluated in two RCTs with successful eradication rates of $84.8 \%(28 / 33 ; 95 \%$ CI, $72.6 \%$ to $97.1 \%)$ after 10 -day therapy and $88.1 \%(126 / 143 ; 95 \% \mathrm{CI}, 81.6 \%$ to $92.9 \%)$ after 14-day therapy after failure of first-line PPI-amoxicillinclarithromycin/metronidazole. ${ }^{144,154}$ Two prospective cohort studies reported that levofloxacin-bismuth quadruple therapy showed $83.8 \%$ (31/37; $95 \%$ CI, $71.3 \%$ to $96.2 \%)$ eradication rate after failure of first-line clarithromycin triple and second-line bismuth quadruple therapy and 90.0\% (180/200; 95\% CI, $85.8 \%$ to $94.2 \%)$ after failure of first-line standard triple or non-bismuth quadruple therapy. ${ }^{192,193}$ However, in an RCT reported from Hong Kong in 2007, levofloxacin-bismuth quadruple therapy achieved successful eradication in $73 \%$ (37/51; $95 \%$ CI, $60.0 \%$ to $85.2 \%$ ) subjects after $\geq 1$ eradication failures, which was inferior to bismuth quadruple therapy. ${ }^{194}$ Therefore, although being expected to be effective, this regimen needs to be validated in Korean population before use.

The levofloxacin sequential regimen (levofloxacin, PPI, amoxicillin, and metronidazole followed by PPI and amoxicillin) also showed promising results in patients failing various first-line triple therapy, with successful eradication rates ranging between $82.2 \%$ and $90.2 \%$ in three RCTs. ${ }^{148,149,160}$ This regimen also needs verification for its efficacy after failure of bismuth quadruple therapy.

\section{(4) Rifabutin containing regimen}

The major limitations of using rifabutin for the eradication of $H$. pylori are high cost, myelotoxicity, and concerns for inducing resistance to Mycobacterium tuberculosis. ${ }^{195}$ Three RCTs comparing rifabutin triple therapy (PPI-amoxicillin-rifabutin) with other regimens as salvage treatment were reported before 2008. ${ }^{196-198}$ A systematic review reported in 2012, which included those three RCTs, showed second-, third-, and forth-line eradication rates of rifabutin triple therapy were $79 \%$ (95\% CI, $67 \%$ to $92 \%$ ), $66 \%$ (95\% CI, $55 \%$ to $77 \%$ ), and $70 \%$ ( $95 \%$ CI, $60 \%$ to $79 \%$ ), respectively. ${ }^{195}$ It is recommended that rifabutin daily dose of 300 $\mathrm{mg}$ and treatment duration of 10 days are appropriate for this regimen. ${ }^{139}$ There were another three RCTs including rifabutin containing regimens in the systematic review for the current guidelines. ${ }^{146,155,156}$ However, no study com- 
pared rifabutin triple therapy with other regimen after failure of bismuth quadruple therapy. They had highly heterogeneous designs among the studies with eradication rates ranging $77.8 \%$ to $96.3 \%$. Therefore, rifabutin triple therapy may be suggested as one of rescue options after previous failure of multiple attempts including bismuth quadruple therapy. Nevertheless, relative lack of evidences and known risks should be carefully considered.

\section{(5) High dose dual therapy}

High dose dual therapy includes amoxicillin $\geq 3 \mathrm{~g}$ administered $\geq 3$ times daily to maintain high trough levels. ${ }^{139}$ Only one RCT found in the systematic review, in which 14-day rabeprazole $20 \mathrm{mg}$ plus amoxicillin $750 \mathrm{mg}$ four times daily achieved eradication rate of $89.3 \%$ (50/56; $95 \%$ CI, $80.9 \%$ to $97.6 \%$ ) in patients with $\geq 1$ eradication failures of unspecified regimens. ${ }^{151}$ Two RCTs conducted before 2008 reported eradication rates of 70\% (95\% CI, 57.5\% to $79.7 \%$ ) and $75.6 \%$ (95\% CI, $59.7 \%$ to $87.6 \%$ ) as salvage therapy. ${ }^{197,199}$ This regimen may also be considered salvage therapy after failure of bismuth quadruple therapy, but more data is required to support this decision.

\section{(6) Concomitant therapy}

Although it is inappropriate to use clarithromycin again after failing clarithromycin containing regimen, CT (PPIamoxicillin-clarithromycin-metronidazole) may be selected as a salvage treatment because combination of clarithromycin and metronidazole may overcome clarithromycin resistance. ${ }^{184}$ However, there was no RCT which evaluated CT after failure of bismuth quadruple therapy in the systematic review. There was only one RCT which showed that 7 -day CT achieved $86.5 \%$ (45/51; 95\% CI, $76.9 \%$ to 96.1\%) after failure of first-line PPI-amoxicillin-clarithromycin. ${ }^{171}$ One prospective cohort study nested in an RCT reported that 10-day CT showed $84.6 \%(11 / 13$; $95 \%$ CI, $57.8 \%$ to $95.7 \%$ ) eradication rate after failure of first-line bismuth quadruple therapy. ${ }^{200}$

\section{SUMMARY AND CONCLUSION}

H. pylori is associated with socioeconomic burdens as it causes various gastrointestinal diseases and has a high prevalence rate of about $50 \%$ in Korea. It is clinically effective to establish therapeutic indications for $H$. pylori and to present effective primary and secondary treatment regimens; this is important and necessary for the efficient use of national medical resources. In recent years, as the resistance rate of $H$. pylori to clarithromycin has increased, the eradication rate of the existing standard triple therapy has tended to decrease. To overcome this, the treatment period has been extended or non-bismuth quadruple therapy such as sequential therapy or CT has been introduced. In the case of salvage therapy, it was difficult to select the right RCTs for each situation due to the diversity of first-line therapy regimens. As a result of meta-analyses of the latest RCTs published, bismuth quadruple therapy is recommended after standard triple therapy, sequential therapy, or CT has failed. If bismuth quadruple therapy is used as the first-line or salvage therapy, levofloxacin triple therapy is recommended. However, its effectiveness may be reduced in areas with high resistance to levofloxacin, such as Korea.

Although recommendations were made according to the resistance rate of Korea, implementing evidence-based medicine and using de novo meta-analysis, but it can also be applied in Far East Asia, which has a similar antibiotic resistance rate as Korea. In addition, recommendation on clarithromycin resistance testing based on PCR or sequencing have been made based on the latest literatures. We believe that the statement regarding tailored therapy will be useful for the use of resistance tests based on PCR or sequencing, which are widely used in clinical practice recently due to the convenience of use.

In this guideline, expert consensus was not reached on indications for eradication therapy for CAG/IM; therefore, further studies are needed to determine whether eradication therapy may lower the incidence of gastric cancer in CAG/IM. In addition, family history of gastric cancer is also a known risk factor of gastric cancer, and further research is needed to establish therapeutic indications for this. Studies on cost-effectiveness according to various combinations of first-line and salvage therapy regimens are also needed in future.

\section{CONFLICTS OF INTEREST}

Y.C.L., a member of the Editor-in-Chief of Gut and Liver, is the corresponding author of this article. However, he played no role whatsoever in the editorial evaluation of this article or the decision to publish it. Except for that, no potential conflict of interest relevant to this article was reported.

\section{ACKNOWLEDGEMENTS}

We thank professor Ein Sun Shin and professor Soo Young Kim for their support in the methodological aspect of this guideline. We would like to express our deep gratitude to Ein Soon Shin, PhD \& MPH, Research Head of the 
Research Agency for Clinical Practice Guidelines of Korean Academy of Medical Sciences for the Meta-Analysis Workshop, and Soo Young Kim, a professor from the Department of Family Medicine, Hallym University College of Medicine for conducting the Workshop on Expert Consensus Method. We also thank Nayoung Kim, a professor from the Department of Internal Medicine, Seoul National University College of Medicine and Kwang Ha Kim, a professor from the Department of Internal Medicine, Pusan University College of Medicine who reviewed the draft of the guidelines by peer review. Finally, we thank the Internet community "Bokanyi" for helping us with the patient preference survey.

This guideline has been published jointly with consent in both the Gut and Liver and The Korean Journal of Helicobacter and Upper Gastrointestinal Research.

\section{ORCID}

Hye-Kyung Jung Seung Joo Kang https://orcid.org/0000-0002-6653-5214 https://orcid.org/0000-0002-7401-8356 Yong Chan Lee https://orcid.org/0000-0001-8800-6906 Hyo-Joon Yang https://orcid.org/0000-0002-0265-672X Seon-Young Park https://orcid.org/0000-0002-0962-5977 Cheol Min Shin https://orcid.org/0000-0003-2265-9845 Sung Eun Kim https://orcid.org/0000-0002-1835-4830 Hyun Chul Lim https://orcid.org/0000-0003-4912-7136 Jie-Hyun Kim https://orcid.org/0000-0002-9198-3326 Su Youn Nam https://orcid.org/0000-0002-5568-7714 Woon Geon Shin https://orcid.org/0000-0002-9851-5576 Jae Myung Park https://orcid.org/0000-0002-1534-7467 Il Ju Choi https://orcid.org/0000-0002-8339-9824 Jae Gyu Kim Miyoung Choi
5. Statistics Korea. Vital Statistics of Korea PeriodAnnual 1970-2018. Daejeon: Statistics Korea; c2019 [cited 2020 Nov 25]. Available from: http://kostat.go.kr/wnsearch/search.jsp.

6. Asaka M, Kato M, Takahashi S, et al. Guidelines for the management of Helicobacter pylori infection in Japan: 2009 revised edition. Helicobacter 2010;15:1-20.

7. Sugano K, Tack J, Kuipers EJ, et al. Kyoto global consensus report on Helicobacter pylori gastritis. Gut 2015;64:13531367.

8. Kim SG, Jung HK, Lee HL, et al. Guidelines for the diagnosis and treatment of Helicobacter pylori infection in Korea, 2013 revised edition. J Gastroenterol Hepatol 2014;29:13711386.

9. Braden B. The best and worst treatments for Helicobacter pylori. BMJ 2015;351:h4146.

10. De Francesco V, Giorgio F, Hassan C, et al. Worldwide H. pylori antibiotic resistance: a systematic review. J Gastrointestin Liver Dis 2010;19:409-414.

11. Malfertheiner P, Megraud F, O'Morain CA, et al. Management of Helicobacter pylori infection: the Maastricht V/ Florence Consensus Report. Gut 2017;66:6-30.

12. Kim JM, Kim JS, Jung HC, Kim N, Kim YJ, Song IS. Distribution of antibiotic MICs for Helicobacter pylori strains over a 16-year period in patients from Seoul, South Korea. Antimicrob Agents Chemother 2004;48:4843-4847.

13. Hwang TJ, Kim N, Kim HB, et al. Change in antibiotic resistance of Helicobacter pylori strains and the effect of A2143G point mutation of $23 \mathrm{~S}$ rRNA on the eradication of $\mathrm{H}$. pylori in a single center of Korea. J Clin Gastroenterol 2010;44:536543.

14. Lee JW, Kim N, Kim JM, et al. Prevalence of primary and secondary antimicrobial resistance of Helicobacter pylori in Korea from 2003 through 2012. Helicobacter 2013;18:206214.

15. Glasier A, Brechin S, Raine R, Penney G. A consensus process to adapt the World Health Organization selected practice recommendations for UK use. Contraception 2003;68:327-333.

16. Higgins JP, Altman DG, Gøtzsche PC, et al. The Cochrane Collaboration's tool for assessing risk of bias in randomised trials. BMJ 2011;343:d5928.

17. Kim SY, Park JE, Lee YJ, et al. Testing a tool for assessing the risk of bias for nonrandomized studies showed moderate reliability and promising validity. J Clin Epidemiol 2013;66:408-414.

18. Schünemann H, Brożek J, Guyatt G, Oxman A. GRADE handbook. London: The Cochrane Collaboration, 2013.

19. Andrews J, Guyatt G, Oxman AD, et al. GRADE guidelines: 14. Going from evidence to recommendations: the significance and presentation of recommendations. J Clin Epidemiol 2013;66:719-725. 
20. Cho JH, Jeon SR, Kim HG, Jin SY, Park S. Cost-effectiveness of a tailored Helicobacter pylori eradication strategy based on the presence of a $23 \mathrm{~S}$ ribosomal RNA point mutation that causes clarithromycin resistance in Korean patients. J Gastroenterol Hepatol 2019;34:700-706.

21. Gweon TG, Kim JS, Kim BW. An economic modeling study of Helicobacter pylori eradication: comparison of dual priming oligonucleotide-based multiplex polymerase chain reaction and empirical treatment. Gut Liver 2018;12:648-654.

22. Jones J, Hunter D. Consensus methods for medical and health services research. BMJ 1995;311:376-380.

23. McLean E, Cogswell M, Egli I, Wojdyla D, de Benoist B. Worldwide prevalence of anaemia, WHO Vitamin and Mineral Nutrition Information System, 1993-2005. Public Health Nutr 2009;12:444-454.

24. Stevens GA, Finucane MM, De-Regil LM, et al. Global, regional, and national trends in haemoglobin concentration and prevalence of total and severe anaemia in children and pregnant and non-pregnant women for 1995-2011: a systematic analysis of population-representative data. Lancet Glob Health 2013;1:e16-e25.

25. Zhang ZW, Patchett SE, Perrett D, Katelaris PH, Domizio P, Farthing MJ. The relation between gastric vitamin C concentrations, mucosal histology, and CagA seropositivity in the human stomach. Gut 1998;43:322-326.

26. Calam J, Gibbons A, Healey ZV, Bliss P, Arebi N. How does Helicobacter pylori cause mucosal damage? Its effect on acid and gastrin physiology. Gastroenterology 1997;113(6 Suppl):S43-S49.

27. Hudak L, Jaraisy A, Haj S, Muhsen K. An updated systematic review and meta-analysis on the association between Helicobacter pylori infection and iron deficiency anemia. Helicobacter 2017;22:e12330.

28. Chen LH, Luo HS. Effects of H pylori therapy on erythrocytic and iron parameters in iron deficiency anemia patients with $\mathrm{H}$ pylori-positive chronic gastristis. World J Gastroenterol 2007;13:5380-5383.

29. Miernyk K, Bruden D, Zanis C, et al. The effect of Helicobacter pylori infection on iron stores and iron deficiency in urban Alaska Native adults. Helicobacter 2013;18:222-228.

30. Monzón H, FornéM, Esteve M, et al. Helicobacter pylori infection as a cause of iron deficiency anaemia of unknown origin. World J Gastroenterol 2013;19:4166-4171.

31. Choi IJ, Kook MC, Kim YI, et al. Helicobacter pylori therapy for the prevention of metachronous gastric cancer. N Engl J Med 2018;378:1085-1095.

32. Fukase K, Kato M, Kikuchi S, et al. Effect of eradication of Helicobacter pylori on incidence of metachronous gastric carcinoma after endoscopic resection of early gastric cancer: an open-label, randomized controlled trial. Lancet 2008;372:392-397.
33. Choi JM, Kim SG, Choi J, et al. Effects of Helicobacter pylori eradication for metachronous gastric cancer prevention: a randomized controlled trial. Gastrointest Endosc 2018;88:475-485.

34. Song JH, Yang SY, Lim JH, Choi JM, Kim SG. The effect of Helicobacter pylori eradication on the metachronous neoplasm after endoscopic resection for gastric dysplasia. Korean J Gastroenterol 2017;70:27-32.

35. Shin SH, Jung DH, Kim JH, et al. Helicobacter pylori eradication prevents metachronous gastric neoplasms after endoscopic resection of gastric dysplasia. PLoS One 2015;10:e0143257.

36. Chon I, Choi C, Shin CM, Park YS, Kim N, Lee DH. Effect of Helicobacter pylori eradication on subsequent dysplasia development after endoscopic resection of gastric dysplasia. Korean J Gastroenterol 2013;61:307-312.

37. Du LJ, Chen BR, Kim JJ, Kim S, Shen JH, Dai N. Helicobacter pylori eradication therapy for functional dyspepsia: systematic review and meta-analysis. World J Gastroenterol 2016;22:3486-3495.

38. Zhao B, Zhao J, Cheng WF, et al. Efficacy of Helicobacter pylori eradication therapy on functional dyspepsia: a metaanalysis of randomized controlled studies with 12-month follow-up. J Clin Gastroenterol 2014;48:241-247.

39. Moayyedi P, Lacy BE, Andrews CN, Enns RA, Howden CW, Vakil N. ACG and CAG clinical guideline: management of dyspepsia. Am J Gastroenterol 2017;112:988-1013.

40. McColl K, Murray L, El-Omar E, et al. Symptomatic benefit from eradicating Helicobacter pylori infection in patients with nonulcer dyspepsia. N Engl J Med 1998;339:1869-1874.

41. Blum AL, Talley NJ, O'Moráin C, et al. Lack of effect of treating Helicobacter pylori infection in patients with nonulcer dyspepsia. Omeprazole plus Clarithromycin and Amoxicillin Effect One Year after Treatment (OCAY) Study Group. N Engl J Med 1998;339:1875-1881.

42. Talley NJ, Vakil N, Ballard ED 2nd, Fennerty MB. Absence of benefit of eradicating Helicobacter pylori in patients with nonulcer dyspepsia. N Engl J Med 1999;341:1106-1111.

43. Talley NJ, Janssens J, Lauritsen K, Rácz I, Bolling-Sternevald E. Eradication of Helicobacter pylori in functional dyspepsia: randomised double blind placebo controlled trial with 12 months' follow up. The Optimal Regimen Cures Helicobacter Induced Dyspepsia (ORCHID) Study Group. BMJ 1999;318:833-837.

44. Koskenpato J, FarkkiläM, Sipponen P. Helicobacter pylori eradication and standardized 3-month omeprazole therapy in functional dyspepsia. Am J Gastroenterol 2001;96:28662872.

45. Hsu PI, Lai KH, Tseng HH, et al. Eradication of Helicobacter pylori prevents ulcer development in patients with ulcer-like functional dyspepsia. Aliment Pharmacol Ther 2001;15:195- 
201.

46. Bruley Des Varannes S, Fléjou JF, Colin R, Zaïm M, Meunier A, Bidaut-Mazel C. There are some benefits for eradicating Helicobacter pylori in patients with non-ulcer dyspepsia. Aliment Pharmacol Ther 2001;15:1177-1185.

47. Froehlich F, Gonvers JJ, Wietlisbach V, et al. Helicobacter pylori eradication treatment does not benefit patients with nonulcer dyspepsia. Am J Gastroenterol 2001;96:2329-2336.

48. Chiba N, Van Zanten SJ, Sinclair P, Ferguson RA, Escobedo $S$, Grace E. Treating Helicobacter pylori infection in primary care patients with uninvestigated dyspepsia: the Canadian adult dyspepsia empiric treatment. Helicobacter pylori positive (CADET-Hp) randomised controlled trial. BMJ 2002;324:1012-1016.

49. Veldhuyzen van Zanten S, Fedorak RN, Lambert J, Cohen L, Vanjaka A. Absence of symptomatic benefit of lansoprazole, clarithromycin, and amoxicillin triple therapy in eradication of Helicobacter pylori positive, functional (nonulcer) dyspepsia. Am J Gastroenterol 2003;98:1963-1969.

50. Malfertheiner P, MOssner J, Fischbach W, et al. Helicobacter pylori eradication is beneficial in the treatment of functional dyspepsia. Aliment Pharmacol Ther 2003;18:615-625.

51. Gisbert JP, Cruzado AI, Garcia-Gravalos R, Pajares JM. Lack of benefit of treating Helicobacter pylori infection in patients with functional dyspepsia: randomized one-year follow-up study. Hepatogastroenterology 2004;51:303-308.

52. Mazzoleni LE, Sander GB, Ott EA, et al. Clinical outcomes of eradication of Helicobacter pylori in nonulcer dyspepsia in a population with a high prevalence of infection: results of a 12-month randomized, double blind, placebo-controlled study. Dig Dis Sci 2006;51:89-98.

53. Ang TL, Fock KM, Teo EK, et al. Helicobacter pylori eradication versus prokinetics in the treatment of functional dyspepsia: a randomized, double-blind study. J Gastroenterol 2006;41:647-653.

54. Gwee KA, Teng L, Wong RK, Ho KY, Sutedja DS, Yeoh KG. The response of Asian patients with functional dyspepsia to eradication of Helicobacter pylori infection. Eur J Gastroenterol Hepatol 2009;21:417-424.

55. Mazzoleni LE, Sander GB, Francesconi CF, et al. Helicobacter pylori eradication in functional dyspepsia: HEROES trial. Arch Intern Med 2011;171:1929-1936.

56. Sodhi JS, Javid G, Zargar SA, et al. Prevalence of Helicobacter pylori infection and the effect of its eradication on symptoms of functional dyspepsia in Kashmir, India. J Gastroenterol Hepatol 2013;28:808-813.

57. Yazdanbod A, Salimian S, Habibzadeh S, Hooshyar A, Maleki N, Norouzvand M. Effect of Helicobacter pylori eradication in Iranian patients with functional dyspepsia: a prospective, randomized, placebo-controlled trial. Arch Med Sci 2015;11:964-969.
58. Kang SJ, Park B, Shin CM. Helicobacter pylori eradication therapy for functional dyspepsia: a meta-analysis by region and H. pylori prevalence. J Clin Med 2019;8:1324.

59. Hooi JKY, Lai WY, Ng WK, et al. Global prevalence of Helicobacter pylori infection: systematic review and metaanalysis. Gastroenterology 2017;153:420-429.

60. Chen HN, Wang Z, Li X, Zhou ZG. Helicobacter pylori eradication cannot reduce the risk of gastric cancer in patients with intestinal metaplasia and dysplasia: evidence from a meta-analysis. Gastric Cancer 2016;19:166-175.

61. Rokkas T, Rokka A, Portincasa P. A systematic review and meta-analysis of the role of Helicobacter pylori eradication in preventing gastric cancer. Ann Gastroenterol 2017;30:414423.

62. Yanaoka K, Oka M, Ohata H, et al. Eradication of Helicobacter pylori prevents cancer development in subjects with mild gastric atrophy identified by serum pepsinogen levels. Int J Cancer 2009;125:2697-2703.

63. Li WQ, Ma JL, Zhang L, et al. Effects of Helicobacter pylori treatment on gastric cancer incidence and mortality in subgroups. J Natl Cancer Inst 2014;106:dju116.

64. Fallone CA, Chiba N, van Zanten SV, et al. The Toronto consensus for the treatment of Helicobacter pylori infection in adults. Gastroenterology 2016;151:51-69.

65. Choi HS, Park DI, Hwang SJ, et al. Double-dose, new-generation proton pump inhibitors do not improve Helicobacter pylori eradication rate. Helicobacter 2007;12:638-642.

66. Kim BG, Lee DH, Ye BD, et al. Comparison of 7-day and 14-day proton pump inhibitor-containing triple therapy for Helicobacter pylori eradication: neither treatment duration provides acceptable eradication rate in Korea. Helicobacter 2007;12:31-35.

67. Kim SY, Lee SW, Jung SW, et al. Comparative study of Helicobacter pylori eradication rates of twice-versus four-timesdaily amoxicillin administered with proton pump inhibitor and clarithromycin: a randomized study. Helicobacter 2008;13:282-287.

68. Kim N, Park SH, Seo GS, et al. Lafutidine versus lansoprazole in combination with clarithromycin and amoxicillin for one versus two weeks for Helicobacter pylori eradication in Korea. Helicobacter 2008;13:542-549.

69. Choi WH, Park DI, Oh SJ, et al. Effectiveness of 10 daysequential therapy for Helicobacter pylori eradication in Korea. Korean J Gastroenterol 2008;51:280-284.

70. Kim MN, Kim N, Lee SH, et al. The effects of probiotics on PPI-triple therapy for Helicobacter pylori eradication. Helicobacter 2008;13:261-268.

71. Jung JM, Shim KN, Oh HJ, et al. Role of anti-secretory treatment in addition to Helicobacter pylori eradication triple therapy in the treatment of peptic ulcer. Korean J Gastroenterol 2008;51:11-18. 
72. Kim HW, Kim GH, Cheong JY, et al. H pylori eradication: a randomized prospective study of triple therapy with or without ecabet sodium. World J Gastroenterol 2008;14:908-912.

73. Lee JH, Jung HY, Choi KD, Song HJ, Lee GH, Kim JH. The influence of CYP2C19 polymorphism on eradication of Helicobacter pylori: a prospective randomized study of lansoprazole and rabeprazole. Gut Liver 2010;4:201-206.

74. Song MJ, Park DI, Park JH, et al. The effect of probiotics and mucoprotective agents on PPI-based triple therapy for eradication of Helicobacter pylori. Helicobacter 2010;15:206-213.

75. Kim YS, Kim SJ, Yoon JH, et al. Randomised clinical trial: the efficacy of a 10-day sequential therapy vs. a 14-day standard proton pump inhibitor-based triple therapy for Helicobacter pylori in Korea. Aliment Pharmacol Ther 2011;34:1098-1105.

76. Choi KH, Chung WC, Lee KM, et al. Efficacy of levofloxacin and rifaximin based quadruple therapy in Helicobacter pylori associated gastroduodenal disease: a double-blind, randomized controlled trial. J Korean Med Sci 2011;26:785790.

77. Chung JW, Jung YK, Kim YJ, et al. Ten-day sequential versus triple therapy for Helicobacter pylori eradication: a prospective, open-label, randomized trial. J Gastroenterol Hepatol 2012;27:1675-1680.

78. Choi HS, Chun HJ, Park SH, et al. Comparison of sequential and 7-, 10-, 14-d triple therapy for Helicobacter pylori infection. World J Gastroenterol 2012;18:2377-2382.

79. Park HG, Jung MK, Jung JT, et al. Randomised clinical trial: a comparative study of 10-day sequential therapy with 7-day standard triple therapy for Helicobacter pylori infection in naïve patients. Aliment Pharmacol Ther 2012;35:56-65.

80. Oh HS, Lee DH, Seo JY, et al. Ten-day sequential therapy is more effective than proton pump inhibitor-based therapy in Korea: a prospective, randomized study. J Gastroenterol Hepatol 2012;27:504-509.

81. Kim SY, Jung SW, Kim JH, et al. Effectiveness of three times daily lansoprazole/amoxicillin dual therapy for Helicobacter pylori infection in Korea. Br J Clin Pharmacol 2012;73:140143.

82. Lee HJ, Kim JI, Cheung DY, et al. Eradication of Helicobacter pylori according to $23 \mathrm{~S}$ ribosomal RNA point mutations associated with clarithromycin resistance. J Infect Dis 2013;208:1123-1130.

83. Kim SY, Lee SW, Hyun JJ, et al. Comparative study of Helicobacter pylori eradication rates with 5-day quadruple "concomitant" therapy and 7-day standard triple therapy. J Clin Gastroenterol 2013;47:21-24.

84. Heo J, Jeon SW, Jung JT, et al. A randomised clinical trial of 10-day concomitant therapy and standard triple therapy for Helicobacter pylori eradication. Dig Liver Dis 2014;46:980984.
85. Park CS, Lee SM, Park CH, et al. Pretreatment antimicrobial susceptibility-guided vs. clarithromycin-based triple therapy for Helicobacter pylori eradication in a region with high rates of multiple drug resistance. Am J Gastroenterol 2014;109:1595-1602.

86. Lee JW, Kim N, Kim JM, et al. A comparison between 15day sequential, 10-day sequential and proton pump inhibitor-based triple therapy for Helicobacter pylori infection in Korea. Scand J Gastroenterol 2014;49:917-924.

87. Lee HJ, Kim JI, Lee JS, et al. Concomitant therapy achieved the best eradication rate for Helicobacter pylori among various treatment strategies. World J Gastroenterol 2015;21:351359.

88. Bang CS, Kim YS, Park SH, et al. Additive effect of pronase on the eradication rate of first-line therapy for Helicobacter pylori infection. Gut Liver 2015;9:340-345.

89. Chung JW, Han JP, Kim KO, et al. Ten-day empirical sequential or concomitant therapy is more effective than triple therapy for Helicobacter pylori eradication: a multicenter, prospective study. Dig Liver Dis 2016;48:888-892.

90. Kim JS, Kim BW, Hong SJ, et al. Sequential therapy versus triple therapy for the first line treatment of Helicobacter pylori in Korea: a nationwide randomized trial. Gut Liver 2016;10:556-561.

91. Kim BJ, Lee H, Lee YC, et al. Ten-day concomitant, 10-day sequential, and 7-day triple therapy as first-line treatment for Helicobacter pylori infection: a nationwide randomized trial in Korea. Gut Liver 2019;13:531-540.

92. Jung YS, Park CH, Park JH, Nam E, Lee HL. Efficacy of Helicobacter pylori eradication therapies in Korea: a systematic review and network meta-analysis. Helicobacter 2017;22:e12389.

93. Liu WZ, Xie Y, Lu H, et al. Fifth Chinese National Consensus Report on the management of Helicobacter pylori infection. Helicobacter 2018;23:e12475.

94. Gao XZ, Qiao XL, Song WC, Wang XF, Liu F. Standard triple, bismuth pectin quadruple and sequential therapies for Helicobacter pylori eradication. World J Gastroenterol 2010;16:4357-4362.

95. Lahbabi M, Alaoui S, El Rhazi K, et al. Sequential therapy versus standard triple-drug therapy for Helicobacter pylori eradication: result of the HPFEZ randomized study. Clin Res Hepatol Gastroenterol 2013;37:416-421.

96. Rakici H, Akdoğan RA, Bedir R, Copur A, Yilmaz A. Comparison of standard triple therapy, sequential therapy and moxifloxacin-based triple therapy for Helicobacter pylori infection: patients' compliance and bacterial eradication rates. J Dig Dis 2014;15:508-513.

97. Molina-Infante J, Perez-Gallardo B, Fernandez-Bermejo M, et al. Clinical trial: clarithromycin vs. levofloxacin in firstline triple and sequential regimens for Helicobacter pylori 
eradication. Aliment Pharmacol Ther 2010;31:1077-1084.

98. Javid G, Zargar SA, Bhat K, et al. Efficacy and safety of sequential therapy versus standard triple therapy in Helicobacter pylori eradication in Kashmir India: a randomized comparative trial. Indian J Gastroenterol 2013;32:190-194.

99. Morse AL, Goodman KJ, Munday R, et al. A randomized controlled trial comparing sequential with triple therapy for Helicobacter pylori in an Aboriginal community in the Canadian North. Can J Gastroenterol 2013;27:701-706.

100. Zhou L, Zhang J, Chen M, et al. A comparative study of sequential therapy and standard triple therapy for Helicobacter pylori infection: a randomized multicenter trial. Am J Gastroenterol 2014;109:535-541.

101. Lee H, Hong SN, Min BH, et al. Comparison of efficacy and safety of levofloxacin-containing versus standard sequential therapy in eradication of Helicobacter pylori infection in Korea. Dig Liver Dis 2015;47:114-118.

102. Greenberg ER, Anderson GL, Morgan DR, et al. 14-day triple, 5-day concomitant, and 10-day sequential therapies for Helicobacter pylori infection in seven Latin American sites: a randomised trial. Lancet 2011;378:507-514.

103. Nasa M, Choksey A, Phadke A, Sawant P. Sequential therapy versus standard triple-drug therapy for Helicobacter pylori eradication: a randomized study. Indian J Gastroenterol 2013;32:392-396.

104. Boal Carvalho P, Magalhães J, Dias de Castro F, Rosa B, Cotter J. Randomized controlled trial for Helicobacter pylori eradication in a naïve Portuguese population: is sequential treatment superior to triple therapy in real world clinical setting? Acta Med Port 2017;30:185-189.

105. Liou JM, Chen CC, Chang CY, et al. Sequential therapy for 10 days versus triple therapy for 14 days in the eradication of Helicobacter pylori in the community and hospital populations: a randomised trial. Gut 2016;65:1784-1792.

106. Phiphatpatthamaamphan K, Vilaichone RK, Siramolpiwat S, et al. Effect of IL-1 polymorphisms, CYP2C19 genotype and antibiotic resistance on Helicobacter pylori eradication comparing between 10-day sequential therapy and 14day standard triple therapy with four-times-daily-dosing of amoxicillin in Thailand: a prospective randomized study. Asian Pac J Cancer Prev 2016;17:1903-1907.

107. Alsohaibani F, Al Ashgar H, Al Kahtani K, et al. Prospective trial in Saudi Arabia comparing the 14-day standard triple therapy with the 10-day sequential therapy for treatment of Helicobacter pylori infection. Saudi J Gastroenterol 2015;21:220-225.

108. Liu KS, Hung IF, Seto WK, et al. Ten day sequential versus 10 day modified bismuth quadruple therapy as empirical firstline and secondline treatment for Helicobacter pylori in Chinese patients: an open label, randomised, crossover trial. Gut 2014;63:1410-1415.
109. Kefeli A, Basyigit S, Yeniova AO, Kefeli TT, Aslan M, Tanas O. Comparison of three different regimens against Helicobacter pylori as a first-line treatment: a randomized clinical trial. Bosn J Basic Med Sci 2016;16:52-57.

110. Sardarian H, Fakheri H, Hosseini V, Taghvaei T, Maleki I, Mokhtare M. Comparison of hybrid and sequential therapies for Helicobacter pylori eradication in Iran: a prospective randomized trial. Helicobacter 2013;18:129-134.

111. Chen KY, Lin TJ, Lin CL, Lee HC, Wang CK, Wu DC. Hybrid vs sequential therapy for eradication of Helicobacter pylori in Taiwan: a prospective randomized trial. World J Gastroenterol 2015;21:10435-10442.

112. Kim SY, Lee SW, Choe JW, et al. Helicobacter pylori eradication rates of concomitant and sequential therapies in Korea. Helicobacter 2017;22:e2441.

113. Molina-Infante J, Romano M, Fernandez-Bermejo M, et al. Optimized nonbismuth quadruple therapies cure most patients with Helicobacter pylori infection in populations with high rates of antibiotic resistance. Gastroenterology 2013;145:121-128.

114. Hong J, Shu X, Liu D, et al. Antibiotic resistance and CYP2C19 polymorphisms affect the efficacy of concomitant therapies for Helicobacter pylori infection: an open-label, randomized, single-centre clinical trial. J Antimicrob Chemother 2016;71:2280-2285.

115. Park SM, Kim JS, Kim BW, Ji JS, Choi H. Randomized clinical trial comparing 10- or 14-day sequential therapy and 10or 14-day concomitant therapy for the first line empirical treatment of Helicobacter pylori infection. J Gastroenterol Hepatol 2017;32:589-594.

116. Liou JM, Fang YJ, Chen CC, et al. Concomitant, bismuth quadruple, and 14-day triple therapy in the first-line treatment of Helicobacter pylori: a multicentre, open-label, randomised trial. Lancet 2016;388:2355-2365.

117. Das R, Sureshkumar S, Sreenath GS, Kate V. Sequential versus concomitant therapy for eradication of Helicobacter pylori in patients with perforated duodenal ulcer: a randomized trial. Saudi J Gastroenterol 2016;22:309-315.

118. Georgopoulos SD, Xirouchakis E, Martinez-Gonzales B, et al. Randomized clinical trial comparing ten day concomitant and sequential therapies for Helicobacter pylori eradication in a high clarithromycin resistance area. Eur J Intern Med 2016;32:84-90.

119. Apostolopoulos P, Koumoutsos I, Ekmektzoglou K, et al. Concomitant versus sequential therapy for the treatment of Helicobacter pylori infection: a Greek randomized prospective study. Scand J Gastroenterol 2016;51:145-151.

120. Zhou L, Zhang J, Song Z, et al. Tailored versus triple plus bismuth or concomitant therapy as initial Helicobacter pylori treatment: a randomized trial. Helicobacter 2016;21:91-99.

121. Gungor G, Baglicakoglu M, Kayacetin E, et al. Current status 
of five different regimens for empiric first-line Helicobacter pylori eradication in Turkey. Digestion 2015;92:55-59.

122. Heo J, Jeon SW, Jung JT, et al. Concomitant and hybrid therapy for Helicobacter pylori infection: a randomized clinical trial. J Gastroenterol Hepatol 2015;30:1361-1366.

123. Cuadrado-Lavín A, Salcines-Caviedes JR, Diaz-Perez A, et al. First-line eradication rates comparing two shortened non-bismuth quadruple regimens against Helicobacter pylori: an open-label, randomized, multicentre clinical trial. J Antimicrob Chemother 2015;70:2376-2381.

124. Molina-Infante J, Lucendo AJ, Angueira T, et al. Optimised empiric triple and concomitant therapy for Helicobacter pylori eradication in clinical practice: the OPTRICON study. Aliment Pharmacol Ther 2015;41:581-589.

125. Ang TL, Fock KM, Song M, et al. Ten-day triple therapy versus sequential therapy versus concomitant therapy as firstline treatment for Helicobacter pylori infection. J Gastroenterol Hepatol 2015;30:1134-1139.

126. McNicholl AG, Marin AC, Molina-Infante J, et al. Randomised clinical trial comparing sequential and concomitant therapies for Helicobacter pylori eradication in routine clinical practice. Gut 2014;63:244-249.

127. Lim JH, Lee DH, Choi C, et al. Clinical outcomes of twoweek sequential and concomitant therapies for Helicobacter pylori eradication: a randomized pilot study. Helicobacter 2013;18:180-186.

128. Georgopoulos S, Papastergiou V, Xirouchakis E, et al. Nonbismuth quadruple "concomitant" therapy versus standard triple therapy, both of the duration of 10 days, for first-line $\mathrm{H}$. pylori eradication: a randomized trial. J Clin Gastroenterol 2013;47:228-232.

129. Wu DC, Hsu PI, Wu JY, et al. Sequential and concomitant therapy with four drugs is equally effective for eradication of H pylori infection. Clin Gastroenterol Hepatol 2010;8:36-41.

130. De Francesco V, Pontone S, Bellesia A, et al. Quadruple, sequential, and concomitant first-line therapies for $\mathrm{H}$. pylori eradication: a prospective, randomized study. Dig Liver Dis 2018;50:139-141.

131. De Francesco V, Hassan C, Ridola L, Giorgio F, Ierardi E, Zullo A. Sequential, concomitant and hybrid first-line therapies for Helicobacter pylori eradication: a prospective randomized study. J Med Microbiol 2014;63(Pt 5):748-752.

132. Huang YK, Wu MC, Wang SS, et al. Lansoprazole-based sequential and concomitant therapy for the first-line Helicobacter pylori eradication. J Dig Dis 2012;13:232-238.

133. Molina-Infante J, Pazos-Pacheco C, Vinagre-Rodriguez G, et al. Nonbismuth quadruple (concomitant) therapy: empirical and tailored efficacy versus standard triple therapy for clarithromycin-susceptible Helicobacter pylori and versus sequential therapy for clarithromycin-resistant strains. Helicobacter 2012;17:269-276.
134. Georgopoulos SD. "Concomitant" or "sequential" eradication of Helicobacter pylori: which regimen comes first? Ann Gastroenterol 2014;27:280-281.

135. Shin WG, Lee SW, Baik GH, et al. Eradication rates of Helicobacter pylori in Korea over the past 10 years and correlation of the amount of antibiotics use: nationwide survey. Helicobacter 2016;21:266-278.

136. Kim BJ, Kim HS, Song HJ, et al. Online registry for nationwide database of current trend of Helicobacter pylori eradication in Korea: interim analysis. J Korean Med Sci 2016;31:1246-1253.

137. Wenzhen Y, Yumin L, Quanlin G, et al. Is antimicrobial susceptibility testing necessary before first-line treatment for Helicobacter pylori infection? Meta-analysis of randomized controlled trials. Intern Med 2010;49:1103-1109.

138. López-Góngora S, Puig I, Calvet X, et al. Systematic review and meta-analysis: susceptibility-guided versus empirical antibiotic treatment for Helicobacter pylori infection. J Antimicrob Chemother 2015;70:2447-2455.

139. Chey WD, Leontiadis GI, Howden CW, Moss SF. ACG clinical guideline: treatment of Helicobacter pylori infection. Am J Gastroenterol 2017;112:212-239.

140. Li BZ, Threapleton DE, Wang JY, et al. Comparative effectiveness and tolerance of treatments for Helicobacter pylori: systematic review and network meta-analysis. BMJ 2015;351:h4052.

141. Yeo YH, Shiu SI, Ho HJ, et al. First-line Helicobacter pylori eradication therapies in countries with high and low clarithromycin resistance: a systematic review and network meta-analysis. Gut 2018;67:20-27.

142. Chung JW, Ha M, Yun SC, et al. Meta-analysis: sequential therapy is superior to conventional therapy for Helicobacter pylori infection in Korea. Korean J Gastroenterol 2013;62:267-271.

143. Gisbert JP, Calvet X. Review article: the effectiveness of standard triple therapy for Helicobacter pylori has not changed over the last decade, but it is not good enough. Aliment Pharmacol Ther 2011;34:1255-1268.

144. Wu TS, Hsu PI, Kuo CH, et al. Comparison of 10-day levofloxacin bismuth-based quadruple therapy and levofloxacinbased triple therapy for Helicobacter pylori. J Dig Dis 2017;18:537-542.

145. Munteanu D, Etzion O, Ben-Yakov G, et al. Efficacy and safety of sequential versus quadruple therapy as second-line treatment for Helicobacter pylori infection: a randomized controlled trial. PLoS One 2017;12:e0183302.

146. Mori H, Suzuki H, Matsuzaki J, et al. Rifabutin-based 10day and 14-day triple therapy as a third-line and fourth-line regimen for Helicobacter pylori eradication: a pilot study. United European Gastroenterol J 2016;4:380-387.

147. Mori H, Suzuki H, Matsuzaki J, et al. Efficacy of 10-day 
sitafloxacin-containing third-line rescue therapies for Helicobacter pylori strains containing the gyrA mutation. Helicobacter 2016;21:286-294.

148. Liou JM, Bair MJ, Chen CC, et al. Levofloxacin sequential therapy vs levofloxacin triple therapy in the second-line treatment of Helicobacter pylori: a randomized trial. Am J Gastroenterol 2016;111:381-387.

149. Chuah SK, Liang CM, Lee CH, et al. A randomized control trial comparing 2 levofloxacin-containing second-line therapies for Helicobacter pylori eradication. Medicine (Baltimore) 2016;95:e3586.

150. Chen Q, Zhang W, Fu Q, et al. Rescue therapy for Helicobacter pylori eradication: a randomized non-inferiority trial of amoxicillin or tetracycline in bismuth quadruple therapy. Am J Gastroenterol 2016;111:1736-1742.

151. Yang JC, Lin CJ, Wang HL, et al. High-dose dual therapy is superior to standard first-line or rescue therapy for Helicobacter pylori infection. Clin Gastroenterol Hepatol 2015;13:895-905.

152. Mansour-Ghanaei F, Joukar F, Naghipour MR, Forouhari A, Saadat SM. Seven-day quintuple regimen as a rescue therapy for Helicobacter pylori eradication. World J Gastroenterol 2015;21:661-666.

153. Jheng GH, Wu IC, Shih HY, et al. Comparison of secondline quadruple therapies with or without bismuth for Helicobacter pylori infection. Biomed Res Int 2015;2015:163960.

154. Cao Z, Chen Q, Zhang W, et al. Fourteen-day optimized levofloxacin-based therapy versus classical quadruple therapy for Helicobacter pylori treatment failures: a randomized clinical trial. Scand J Gastroenterol 2015;50:1185-1190.

155. Lim HC, Lee YJ, An B, Lee SW, Lee YC, Moon BS. Rifabutinbased high-dose proton-pump inhibitor and amoxicillin triple regimen as the rescue treatment for Helicobacter pylori. Helicobacter 2014;19:455-461.

156. Ierardi E, Giangaspero A, Losurdo G, et al. Quadruple rescue therapy after first and second line failure for Helicobacter pylori treatment: comparison between two tetracyclinebased regimens. J Gastrointestin Liver Dis 2014;23:367-370.

157. Murakami K, Furuta T, Ando T, et al. Multi-center randomized controlled study to establish the standard third-line regimen for Helicobacter pylori eradication in Japan. J Gastroenterol 2013;48:1128-1135.

158. Moon JY, Kim GH, You HS, et al. Levofloxacin, metronidazole, and lansoprazole triple therapy compared to quadruple therapy as a second-line treatment of Helicobacter pylori infection in Korea. Gut Liver 2013;7:406-410.

159. Kuo CH, Hsu PI, Kuo FC, et al. Comparison of 10 day bismuth quadruple therapy with high-dose metronidazole or levofloxacin for second-line Helicobacter pylori therapy: a randomized controlled trial. J Antimicrob Chemother 2013;68:222-228.
160. Calhan T, Kahraman R, Sahin A, et al. Efficacy of two levofloxacin-containing second-line therapies for Helicobacter pylori: a pilot study. Helicobacter 2013;18:378-383.

161. Yoon JH, Baik GH, Kim YS, et al. Comparison of the eradication rate between 1 - and 2-week bismuth-containing quadruple rescue therapies for Helicobacter pylori eradication. Gut Liver 2012;6:434-439.

162. Chuah SK, Tai WC, Hsu PI, et al. The efficacy of second-line anti-Helicobacter pylori therapy using an extended 14-day levofloxacin/amoxicillin/proton-pump inhibitor treatment: a pilot study. Helicobacter 2012;17:374-381.

163. Chuah SK, Hsu PI, Chang KC, et al. Randomized comparison of two non-bismuth-containing second-line rescue therapies for Helicobacter pylori. Helicobacter 2012;17:216223.

164. Wu DC, Hsu PI, Tseng HH, et al. Helicobacter pylori infection: a randomized, controlled study comparing 2 rescue therapies after failure of standard triple therapies. Medicine (Baltimore) 2011;90:180-185.

165. Hu TH, Chuah SK, Hsu PI, et al. Randomized comparison of two nonbismuth-containing rescue therapies for Helicobacter pylori. Am J Med Sci 2011;342:177-181.

166. Gu LY, Lin WW, Lu H, Chen XY, Ge ZZ, Li XB. Quadruple therapy with medications containing either rufloxacin or furazolidone as a rescue regimen in the treatment of Helicobacter pylori-infected dyspepsia patients: a randomized pilot study. Helicobacter 2011;16:284-288.

167. Chung JW, Lee JH, Jung HY, et al. Second-line Helicobacter pylori eradication: a randomized comparison of 1-week or 2-week bismuth-containing quadruple therapy. Helicobacter 2011;16:289-294.

168. Minakari M, Davarpanah Jazi AH, Shavakhi A, Moghareabed N, Fatahi F. A randomized controlled trial: efficacy and safety of azithromycin, ofloxacin, bismuth, and omeprazole compared with amoxicillin, clarithromycin, bismuth, and omeprazole as second-line therapy in patients with Helicobacter pylori infection. Helicobacter 2010;15:154-159.

169. Lee BH, Kim N, Hwang TJ, et al. Bismuth-containing quadruple therapy as second-line treatment for Helicobacter pylori infection: effect of treatment duration and antibiotic resistance on the eradication rate in Korea. Helicobacter 2010;15:38-45.

170. Kuo CH, Wang SS, Hsu WH, et al. Rabeprazole can overcome the impact of CYP2C19 polymorphism on quadruple therapy. Helicobacter 2010;15:265-272.

171. Ueki N, Miyake K, Kusunoki M, et al. Impact of quadruple regimen of clarithromycin added to metronidazole-containing triple therapy against Helicobacter pylori infection following clarithromycin-containing triple-therapy failure. Helicobacter 2009;14:91-99.

172. Kuo CH, Hu HM, Kuo FC, et al. Efficacy of levofloxacin- 
based rescue therapy for Helicobacter pylori infection after standard triple therapy: a randomized controlled trial. J Antimicrob Chemother 2009;63:1017-1024.

173. Karatapanis S, Skorda L, Georgopoulos S, et al. Levofloxacin-based triple therapy versus bismuth-based quadruple therapy as a second line treatment for the eradication of $\mathrm{H}$. pylori infection. Ann Gastroenterol 2009;22:263-267.

174. Di Caro S, Franceschi F, Mariani A, et al. Second-line levofloxacin-based triple schemes for Helicobacter pylori eradication. Dig Liver Dis 2009;41:480-485.

175. Bago J, Pevec B, TomićM, MarusićM, Bakula V, Bago P. Second-line treatment for Helicobacter pylori infection based on moxifloxacin triple therapy: a randomized controlled trial. Wien Klin Wochenschr 2009;121:47-52.

176. Uygun A, Ozel AM, Yildiz O, et al. Comparison of three different second-line quadruple therapies including bismuth subcitrate in Turkish patients with non-ulcer dyspepsia who failed to eradicate Helicobacter pylori with a 14-day standard first-line therapy. J Gastroenterol Hepatol 2008;23:4245.

177. Sanches B, Coelho L, Moretzsohn L, Vieira G Jr. Failure of Helicobacter pylori treatment after regimes containing clarithromycin: new practical therapeutic options. Helicobacter 2008;13:572-576.

178. Nishizawa T, Suzuki H, Nakagawa I, Iwasaki E, Masaoka T, Hibi T. Gatifloxacin-based triple therapy as a third-line regimen for Helicobacter pylori eradication. J Gastroenterol Hepatol 2008;23 Suppl 2:S167-S170.

179. Jung HS, Shim KN, Baik SJ, et al. Efficacy of levofloxacinbased triple therapy as second-line Helicobacter pylori eradication. Korean J Gastroenterol 2008;51:285-290.

180. Gisbert JP, Morena F. Systematic review and meta-analysis: levofloxacin-based rescue regimens after Helicobacter pylori treatment failure. Aliment Pharmacol Ther 2006;23:35-44.

181. Saad RJ, Schoenfeld P, Kim HM, Chey WD. Levofloxacinbased triple therapy versus bismuth-based quadruple therapy for persistent Helicobacter pylori infection: a metaanalysis. Am J Gastroenterol 2006;101:488-496.

182. An B, Moon BS, Kim H, et al. Antibiotic resistance in Helicobacter pylori strains and its effect on $\mathrm{H}$. pylori eradication rates in a single center in Korea. Ann Lab Med 2013;33:415419.

183. Kim JM, Kim JS, Kim N, Jung HC, Song IS. Distribution of fluoroquinolone MICs in Helicobacter pylori strains from Korean patients. J Antimicrob Chemother 2005;56:965-967.

184. Graham DY, Lee YC, Wu MS. Rational Helicobacter pylori therapy: evidence-based medicine rather than medicinebased evidence. Clin Gastroenterol Hepatol 2014;12:177186.

185. Marin AC, McNicholl AG, Gisbert JP. A review of rescue regimens after clarithromycin-containing triple therapy failure (for Helicobacter pylori eradication). Expert Opin Pharmacother 2013;14:843-861.

186. Malfertheiner P, Megraud F, O'Morain CA, et al. Management of Helicobacter pylori infection: the Maastricht IV/ Florence Consensus Report. Gut 2012;61:646-664.

187. Liou JM, Chen PY, Luo JC, et al. Efficacies of genotypic resistance-guided vs empirical therapy for refractory Helicobacter pylori infection. Gastroenterology 2018;155:11091119.

188. Gisbert JP; H. pylori Study Group of the Spanish Gastroenterology Association. Letter: third-line rescue therapy with levofloxacin after failure of two treatments to eradicate Helicobacter pylori infection. Aliment Pharmacol Ther 2012;35:1484-1485.

189. Lim JH, Kim SG, Song JH, et al. Efficacy of levofloxacinbased third-line therapy for the eradication of Helicobacter pylori in peptic ulcer disease. Gut Liver 2017;11:226-231.

190. Gisbert JP, Romano M, Molina-Infante J, et al. Two-week, high-dose proton pump inhibitor, moxifloxacin triple Helicobacter pylori therapy after failure of standard triple or non-bismuth quadruple treatments. Dig Liver Dis 2015;47:108-113.

191. Kang KK, Lee DH, Oh DH, et al. Helicobacter pylori eradication with moxifloxacin-containing therapy following failed first-line therapies in South Korea. World J Gastroenterol 2014;20:6932-6938.

192. Gisbert JP, Romano M, Gravina AG, et al. Helicobacter pylori second-line rescue therapy with levofloxacin- and bismuth-containing quadruple therapy, after failure of standard triple or non-bismuth quadruple treatments. Aliment Pharmacol Ther 2015;41:768-775.

193. Hsu PI, Wu DC, Chen A, et al. Quadruple rescue therapy for Helicobacter pylori infection after two treatment failures. Eur J Clin Invest 2008;38:404-409.

194. Yee YK, Cheung TK, Chu KM, et al. Clinical trial: levofloxacin-based quadruple therapy was inferior to traditional quadruple therapy in the treatment of resistant Helicobacter pylori infection. Aliment Pharmacol Ther 2007;26:10631067.

195. Gisbert JP, Calvet X. Review article: rifabutin in the treatment of refractory Helicobacter pylori infection. Aliment Pharmacol Ther 2012;35:209-221.

196. Navarro-Jarabo JM, Fernández N, Sousa FL, et al. Efficacy of rifabutin-based triple therapy as second-line treatment to eradicate Helicobacter pylori infection. BMC Gastroenterol 2007;7:31.

197. Miehlke S, Hansky K, Schneider-Brachert W, et al. Randomized trial of rifabutin-based triple therapy and high-dose dual therapy for rescue treatment of Helicobacter pylori resistant to both metronidazole and clarithromycin. Aliment Pharmacol Ther 2006;24:395-403. 
198. Perri F, Festa V, Clemente R, et al. Randomized study of two "rescue" therapies for Helicobacter pylori-infected patients after failure of standard triple therapies. Am J Gastroenterol 2001;96:58-62.

199. Miehlke S, Kirsch C, Schneider-Brachert W, et al. A prospective, randomized study of quadruple therapy and high-dose dual therapy for treatment of Helicobacter pylori resistant to both metronidazole and clarithromycin. Helicobacter 2003;8:310-319.

200. Liou JM, Chen CC, Chen MJ, et al. Sequential versus triple therapy for the first-line treatment of Helicobacter pylori: a multicentre, open-label, randomised trial. Lancet 2013;381:205-213.

201. Correa P, Fontham ET, Bravo JC, et al. Chemoprevention of gastric dysplasia: randomized trial of antioxidant supplements and anti-Helicobacter pylori therapy. J Natl Cancer Inst 2000;92:1881-1888.

202. Leung WK, Lin SR, Ching JY, et al. Factors predicting progression of gastric intestinal metaplasia: results of a randomised trial on Helicobacter pylori eradication. Gut 2004;53:1244-1249.
203. Wong BC, Lam SK, Wong WM, et al. Helicobacter pylori eradication to prevent gastric cancer in a high-risk region of China: a randomized controlled trial. JAMA 2004;291:187194.

204. Saito D, Boku N, Fujioka T, et al. Impact of H-pylori eradication on gastric cancer prevention: endoscopic results of the Japanese intervention trial (JITHP-study): a randomized multi-center trial. Gastroenterology 2005;128:A4.

205. Wong BC, Zhang L, Ma JL, et al. Effects of selective COX-2 inhibitor and Helicobacter pylori eradication on precancerous gastric lesions. Gut 2012;61:812-818.

206. Songür Y, Senol A, Balkarli A, Baştürk A, Cerçi S. Triple or quadruple tetracycline-based therapies versus standard triple treatment for Helicobacter pylori treatment. Am J Med Sci 2009;338:50-53.

207. Sapmaz F, Kalkan IH, Atasoy P, Basyigit S, Guliter S. A noninferiority study: modified dual therapy consisting higher doses of rabeprazole is as successful as standard quadruple therapy in eradication of Helicobacter pylori. Am J Ther 2017;24:e393-e398. 